\title{
Interaction effects of region-level GDP per capita and age on labour market transition rates in Italy
}

\author{
Luca Zanin ${ }^{1 *}$ and Raffaella Calabrese ${ }^{2}$
}

\author{
*Correspondence: \\ luca.zanin@studio.unibo.it \\ 'Prometeia, G. Marconi, Bologna \\ 40122, Italy \\ Full list of author information is \\ available at the end of the article
}

\begin{abstract}
The aim of this paper is to measure the effect of the interaction between age for the population of males and females aged 18 to 74 and region-level GDP per capita on labour market transition probabilities in Italy. We compare different occupational states in a sample of males and females who remained in their region of residence at two points in time (12 months apart). We estimate the transition probabilities using a flexible hierarchical logit model with interaction effects between worker age and region-level GDP per capita. We apply this model using longitudinal data from the Italian Labour Force Survey that cover the 2004-2013 period. We find empirical support for the assumption that people in the same age cohort have different labour market opportunities based on the level of GDP per capita in their region of residence. These differences are particularly relevant among younger workers.
\end{abstract}

JEL Classification: C14, J01, J21, J68

Keywords: Transition probabilities, Flexible hierarchical logit model, Tensor interaction product, Markov chain framework, Labour market policies

\section{Introduction}

The global financial crisis of 2007-2008 was a significant economic shock. Among its many consequences, negative long-term labour market effects have been officially recorded in many developed countries, including Italy (e.g. Edely 2009; Zanin and Marra 2012; Arechavala et al. 2015; Zanin 2014; Zanin 2016). According to official statistics for the Italian labour market, over three million people were unemployed at the end of 2014 in contrast to the 1.5 million who were unemployed in 2007. During this time, Italy experienced a gross domestic product (GDP) loss of approximately 150 billion euros (at constant 2010 prices). Recent studies have also found evidence of a competitive setback compared to other European countries (see for example Cirillo and Guarasco 2015).

In response to the weak economic recovery over the last few years, the Italian government has introduced some reforms in order to promote economic growth, as well as to increase the flexibility and competitiveness of the country. Regarding the labour market, Law n. 183 of 10 December 2014 (also known as the Jobs Act) modified and integrated the pre-existing normative framework. Specifically, the main aims of the Jobs Act are to (a) increase employment and reduce the share of the workforce with precarious contracts and to (b) stimulate enterprise productivity by encouraging the employment of a young labour

(c) The Author(s). 2017 Open Access This article is distributed under the terms of the Creative Commons Attribution 4.0 International License (http://creativecommons.org/licenses/by/4.0/), which permits unrestricted use, distribution, and reproduction in any medium, provided you give appropriate credit to the original author(s) and the source, provide a link to the Creative Commons license, and indicate if changes were made. 
force, thereby improving growth and competitiveness through reduced labour costs. Since the mid-90s, the gradual reform of the labour market has led the country towards a more flexible structure (for example, the use of additional types of employment contracts, the introduction of policies to facilitate the entry of young people into the labour market, the creation of work agencies, and the management of unemployment assistance).

The most important reforms implemented before the Jobs Act that affected the Italian labour market are Treu Package (1997), Biagi reform (September 2010), and the Fornero (June 2012). The first represents an attempt towards the labour market liberalisation, introducing new atypical contracts, fiscal treatment of part-time work, and work agencies. The second outlined a framework for non-standard contracts and placement system management (e.g. work agencies, job placement offices at universities). The last reform introduced new rules for several labour contracts, a new social welfare system, a crackdown on VAT registration abuse, among others. The maim aims of this sequence of reforms, such as increasing employment levels for young people and women, are established by the Europe 2020 agenda (https://ec.europa.eu/info/strategy/europeansemester_en).

Some analyses on labour market dynamics can increase the effectiveness of labour market reforms. For instance, some empirical results show that temporary contracts can act as a stepping stone to permanent employment, particularly for young people (e.g. Gagliarducci 2005; Barbieri and Sesisto 2008; Barbieri and Scherer 2009; Picchio 2008; Berton et al. 2011). Gagliarducci (2005) shows that the probability of transitioning from a temporary to a permanent job is associated with the duration of the contract, whereas an inverse relationship has been observed when temporary jobs are repeatedly interrupted. Specifically, Berton et al. (2011) found that fixed-term contracts represent points of entry into permanent contracts with the same employer but not with a new employer. Moreover, Barbieri and Scherer (2009) noted that the stepping stone effect is hampered by discrimination against young workers, women, southern Italian workers, and less-educated workers see also Contini and Rapiti (1999). They also found that atypical employment can negatively impact future career prospects. Other studies have shown that the probability of transitioning to permanent employment is highest for the most highly educated, young workers who have not been unemployed, are employed at medium-large private firms, and do not have repeated atypical employment experiences (e.g. Russo et al. 1997; Contini and Rapiti 1999; Gagliarducci 2005). Flisi and Morciano (2011) also suggest that highly educated people are less likely than less-educated people to transition from full-time employment to a 'worse' work state.

Mussida (2010) shows that the difficulty of finding a job increases with unemployment duration. Fabrizi and Mussida (2009) found that gender has an important impact on the probability of transition from unemployment. They found that unemployed males have a greater chance of transitioning to employment than unemployed females. Furthermore, females are more likely than males to become inactive after a period of unemployment, reflecting a discouragement effect. Work experience is another important determinant of the transition probability to employment (e.g. Fabrizi and Mussida 2009; Baussola and Mussida 2014). Flisi and Morciano (2011) showed some evidence about regional differences in labour market transitions in Italy. Specifically, they observed higher probabilities of being unemployed or inactive in the central areas 
and, in particular, in southern Italy than those observed in the Northern part of the country. However, they did not provide empirical evidence of spatial differences by age cohort.

The main aim of this paper is to analyse the interaction effects between region-level GDP per capita and individual age on labour market transition rates. We consider the GDP as a proxy for local economic characteristics and opportunities. There is a lack in the literature about labour market transition probabilities by age cohort based on the economic context in which an individual lives. This paper attempts to fill this gap. For example, a young individual who lives in an area with good economic characteristics should have more labour market opportunities than one who lives in an area with poor economic characteristics. We analyse the Italian labour market, characterised by low internal labour mobility due to frictional effects such as distance, transaction costs, and regional amenities (for further details, see for example Faini et al. 1997; Ward-Warmedinger and Macchiarelli 2013). Given the low worker mobility in Italy, we exclude from this analysis the transition probabilities of people who are moving during the analysed period.

In this paper, we use pooled longitudinal data from the Labour Force Survey (LFS) collected by the Italian Institute for National Statistics (ISTAT). The microdata cover a 10 -year period from 2004 to 2013 . The labour market transitions are analysed by comparing the occupational statuses of males and females over a 12-month period. Previous studies used a Markovian modelling framework (Poterba and Summers 1995; Egger et al. 2007) to analyse labour transition probabilities. From a methodological prospective, the transition probabilities for different states have been mainly studied using fully parametric multinomial logit (MNL) model frameworks (e.g. Fabrizi and Mussida 2009; Flisi and Morciano 2011; Baussola and Mussida 2014).

However, such a modelling framework has two main drawbacks. Firstly, a MNL model relies on the independence of irrelevant alternative assumption, which means that the relative odds of any two outcomes are independent of the number and nature of the other outcomes being simultaneously considered (McFadden 1973). Secondly, parametric models require the imposition of a priori assumptions about the relationships between the continuous covariates and the outcome (e.g. Wood 2006a). As regards this second drawback, two main approaches have been used to analyse the dependence between the age of an individual and the probability of a labour market transition. In the first approach, some authors have used a second-order polynomial to explore possible non-linear dependence between these two variables (e.g. Fabrizi and Mussida 2009; Constant and Zimmermann 2014). In the second one, other authors have instead specified age as a categorical variable defined after grouping individuals. Therefore, some a priori assumptions are used based on pre-defined cut-off values of the continuous covariate. Moreover, the estimated effects are flat within the age range of each categorical variable. The previous approaches cannot capture complex non-linearities, which could lead to a biased interpretation of the results (e.g. Zanin and Marra 2012). Relaxing the assumptions of specific functional forms in studying socio-economic relationships is important to minimise specification errors and to allow the data to offer the best insights into the relationship investigated. This aim can be achieved using a penalised smoothing spline approach. In general, splines represent a valid tool when a functional shape is not known a priori, and a penalty prevents overfitting problems. 
For our case study, we propose a hierarchical additive logit model with interactions to estimate transition probabilities in the labour market. Thanks to the nested structure (Tutz 2012), we can remove the independence of irrelevant alternative assumption. The implementation of splines removes a priori assumptions on the dependence structure (Wood 2006a). Furthermore, our interest is estimating the joint effect of the interaction between region-level GDP per capita and worker age. In this regard, the statistical literature on the generalised additive model (GAM, Wood 2006a) suggests the use of a tensor product specification to estimate the interaction of two continuous covariates (Wood 2006a; Wood 2006b).

The empirical results confirm the existence of a joint effect between region-level GDP per capita and worker age on labour market transition rates in Italy. This supports our assumption of different labour market transition probabilities based on the phase of the life cycle and the economic characteristics of the territory, ceteris paribus. For example, we observe that for a young male (20-30 years old) with a high school diploma and employed under a fixed-term contract in a small service sector firm, the probability that he remains employed in the next 12 months when residing in a territory with a mediumhigh GDP per capita (more than 25,000 euros) is two times higher than that for individuals with the same characteristics but residing in an area with a low GDP per capita (less than 15-20,000 euros). This gap is slightly larger for females. The probability that a female employed at time $T$ is unemployed in the next 12 months when residing in a region with a medium-high GDP per capita (more than 25,000 euros) is four times lower than that for females residing in an area with a low GDP per capita (less than 15-20,000 euros). Similar gaps were observed for the probability of transitioning from unemployment to employment. For workers of both genders, the probability of transitioning to employment from unemployment at older ages seems to be a cross-cutting issue, independent of the level of regional GDP per capita. A caveat in interpreting the results of our analysis is that we take into account only people who do not migrate to a different area of residence during the two observation periods (for instance, from an area with a low GDP per capita to another area with a high GDP per capita).

An underlying message of the results is the difficulty that policy-makers in the country face in reaching the labour market aims of the Europe 2020 plan, especially for young and female workers (see Fana et al. 2015). We suggest that to improve employment levels, the introduced labour market policies should be accompanied by important investments, such as industrial and infrastructure projects, in order to improve the economic conditions of the territory, especially in the most disadvantaged areas of the country. This combination is necessary in order to create conditions that encourage the establishment of production systems that are able to create job opportunities and, hence, foster economic growth and employment (see also Dreger and Reimers 2016; Ghoshray et al. 2016). A natural extension of the present study is a focus on the joint effect of the life cycle and the economic characteristics of a territory among people who are willing to relocate in search of the best job opportunities.

The remainder of this article is organised as follows. In Section 2, we present the methodology used to estimate labour market transition probabilities. In Section 3, we provide insights regarding the data and some descriptive statistics, and we discuss the main results in Section 4. Section 5 provides the main conclusions of the study. 


\section{Methodology}

\subsection{The Markov chain framework}

We assume that an individual of working age can be categorised into one of the following three states: employed, unemployed, or inactive. Employed and unemployed individuals are considered part of the labour force. The three labour market states explored are defined as follows:

- Employed (coded as '0'): people aged 18 to 74 years who, during the week to which the information refers, (a) participated in at least one hour of work in any activity that provides monetary or in-kind compensation, (b) participated in at least $1 \mathrm{~h}$ of unpaid work in the family firm for which they work regularly, or (c) were absent from work (e.g. due to holiday or illness). Employees absent from work are considered employed if the absence does not exceed 3 months or if they continue to receive at least $50 \%$ of their salary during the absence. Self-employed persons absent from work, except for family workers, are considered employed if they remain active during the absence. Family workers are considered employed if the absence does not exceed 3 months.

- Unemployed (coded as ' 1 '): people aged 18 to 74 years who reported at least one active job search action and were willing to work (or to start their own business).

- Inactive (coded as ' 2 '): people aged 18 to 74 years who are not part of the labour force, i.e. are not classified as employed or unemployed. For example, we consider students, homemakers, and people with disabilities as inactive. Retired persons are excluded from our analysis.

The state of an individual in the labour market can change over time. Following the literature, we study the flows into and out of the labour market using a Markov process of order one (see for example Constant and Zimmermann 2014). Briefly, a Markov chain is based on the idea that the state of an individual at time $T$ influences the probability of that individual being in a different state at time $T+1$ (Papoulis 1984). The estimation of transition probabilities using a Markov chain framework assumes that the system converges and is in a steady state, which means that the probability does not depend on the observational period (Constant and Zimmermann 2014, p. 57). To introduce the notation used throughout the paper, the transition matrix for the labour market is defined as follows:

$$
\left(\begin{array}{llll}
P 00 & P 01 & P 02 \\
P 10 & P 11 & P 12 \\
P 20 & P 21 & P 22
\end{array}\right)
$$

where the sum of each row is equal to 1 . In this matrix, $P 00$ is the probability that an individual who is currently employed will be employed in the next 12 months, $P 01$ is the probability that an individual who is currently employed becomes unemployed over the next 12 months, and P02 is the probability that an individual who is currently employed becomes inactive over the next 12 months. A similar interpretation can be made for the transition probabilities from the unemployed $(P 10, P 11$, and $P 12)$ and inactive $(P 20, P 21$, and P22) states.

\subsection{The econometric model}

As mentioned in Section 1, we study labour market transitions by defining a hierarchy of nested comparisons between two subsets of responses by using a logistic additive model 
for each comparison (see the motivations in Section 1). The hierarchical structure is obtained by first modelling the response in groups of homogeneous response categories and then the response within restricted groups (e.g. Tutz 2012).

Figure 1 shows the sequential approach that we briefly present below.

Transitions from the employed state in the hierarchical framework: for the sample of employed workers at time $\mathrm{T}$, in the first step, we study the probability of exiting from the labour force in the next 12 months (that is, of becoming inactive) rather than remaining in the labour force as employed or unemployed workers. In the second step, for the sample of people who remained in the labour force, we study the probability of becoming unemployed rather than remaining employed.

Transitions from the unemployed state in the hierarchical framework: for the sample of unemployed workers at time $T$, in the first step, we study the probability of exiting from the labour force in the next 12 months (that is, of becoming inactive) rather than remaining in the labour force as unemployed or employed workers. In the second step, for the sample of people who remained in the labour force, we study the probability of becoming employed rather than remaining unemployed.

Transitions from the inactive state in the hierarchical framework: for the sample of inactive people at time $T$ (not in the labour force and not labour income earners), in the first step, we study the probability of finding a job and becoming a labour income earner in the next 12 months compared to that of not being a labour income earner, that is, unemployed or inactive. In the second step, for the sample of people who are not labour income earners (unemployed or inactive), we study the probability that an individual engages in an active job search (i.e. becomes an unemployed worker) rather than remaining inactive (i.e. without taking action to start a job search) ${ }^{1}$.

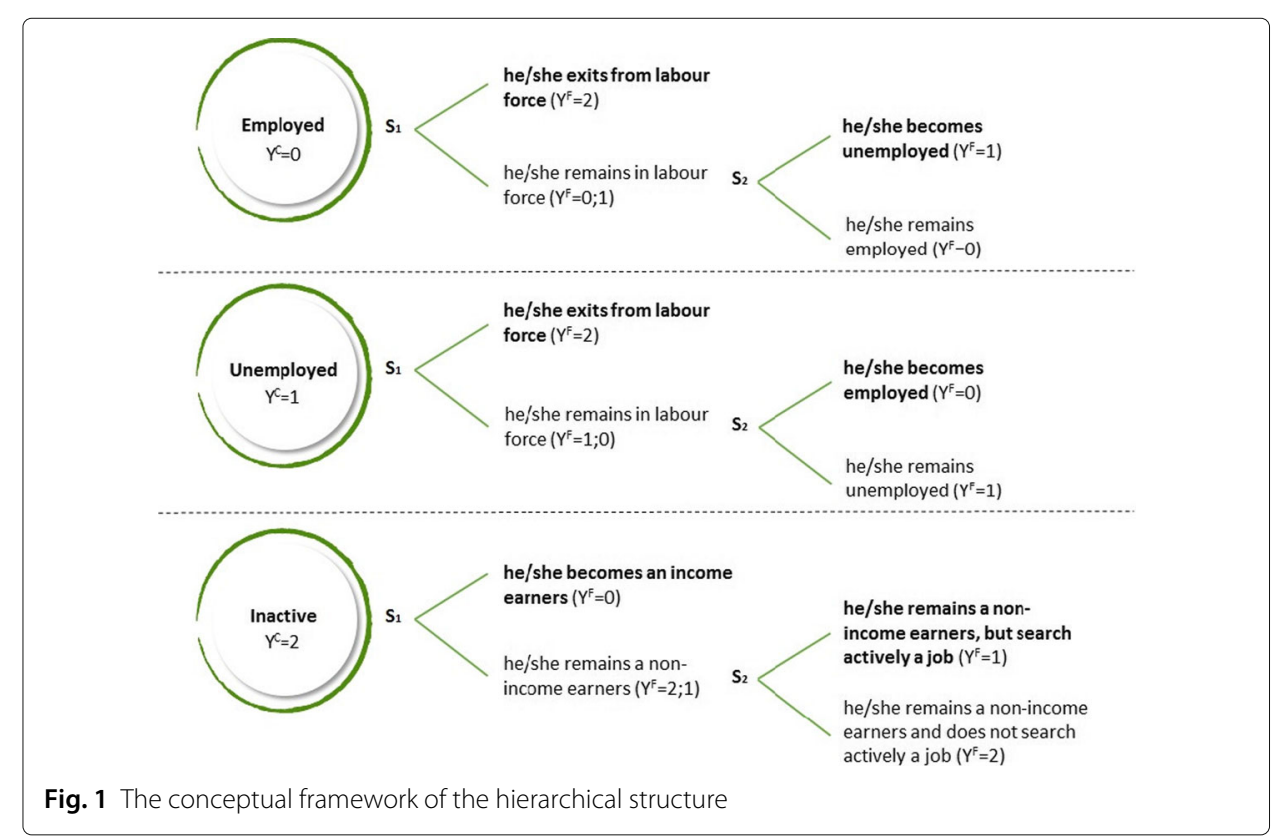


The response categories $K=\{0,1,2\}$, where 0 denotes employed, 1 unemployed, and 2 inactive, are subdivided into two sets $S_{1}$ and $S_{2}$ where $K=S_{1} \cup S_{2}$. We denote the current state as $Y^{C}$ and the future state as $Y^{F}$. In the first step, the additive logistic model is:

$$
P\left(Y^{F} \in S_{1} \mid Y^{C}, \mathbf{x}\right)=\frac{1}{1+\exp \left[-\alpha-\sum_{i=1}^{t} \gamma_{i} z_{i}-f_{\text {age, } g d p}(\text { age }, g d p)-\sum_{j=1}^{p} f_{j}\left(x_{j}\right)\right]}
$$

where $\alpha$ is the intercept, $z_{i}$ with $i=1,2, \ldots, t$ constitutes the discrete covariates with corresponding parameters $\gamma_{i}, f_{j}(\cdot)$ constitutes the unknown one-dimensional smooth functions of the $p$ continuous control variables, and $f_{\text {age,gdp }}$ represents a two-dimensional tensor product smoother for region-level GDP per capita and worker age. The tensor product smoother allows us to study the interaction between the two continuous covariates of interest without imposing an a priori hypothesis about the structure of dependence on the outcome (e.g. linearity or non-linearity).

If the current state is inactive $\left(Y^{C}=2\right)$, the sets are $S_{1}=\{0\}$ and $S_{2}=\{2,1\}$; otherwise, $S_{1}=\{2\}$ and $S_{2}=\{0,1\}$. In the second step, we compute the conditional probability given that the future state belongs to $S_{2}$ :

$$
P\left(Y^{F}=1 \mid Y^{F} \in S_{2}, Y^{C}=0, \mathbf{x}\right)=\frac{1}{1+\exp \left[-\alpha_{1}-\sum_{i=1}^{t} \gamma_{1 i} z_{i}-f_{1 ; \text { age }, g d p}(\text { age }, g d p)-\sum_{j=1}^{p} f_{1 j}\left(x_{j}\right)\right]}
$$

$$
P\left(Y^{F}=0 \mid Y^{F} \in S_{2}, Y^{C}=1, \mathbf{x}\right)=\frac{1}{1+\exp \left[-\alpha_{2}-\sum_{i=1}^{t} \gamma_{2 i} z_{i}-f_{2 ; \text { age }, g d p}(\text { age }, g d p)-\sum_{j=1}^{p} f_{2 j}\left(x_{j}\right)\right]}
$$

$$
P\left(Y^{F}=1 \mid Y^{F} \in S_{2}, Y^{C}=2, \mathbf{x}\right)=\frac{1}{1+\exp \left[-\alpha_{3}-\sum_{i=1}^{t} \gamma_{3 i} z_{i}-f_{3 ; \text { age }, g d p}(\text { age, } g d p)-\sum_{j=1}^{p} f_{3 j}\left(x_{j}\right)\right]}
$$

where $\alpha_{1}, \alpha_{2}$, and $\alpha_{3}$ are the intercepts; $z_{1 i}, z_{2 i}$, and $z_{3 i}$, with $i=1,2, \ldots, t$, are the discrete covariates with corresponding parameters $\gamma_{1 i}, \gamma_{2 i}$, and $\gamma_{3 i}$, respectively; $f_{1 j}(\cdot), f_{2 j}(\cdot)$, and $f_{3 j}(\cdot)$ are the unknown one-dimensional smooth functions of the $p$ continuous covariates; $x_{j}$ is included as control variables; and $f_{1 ; a g e, g d p}, f_{2 ; a g e, g d p}$, and $f_{3 ; \text { age,gdp }}$ are the two-dimensional tensor product smoothers for region-level GDP per capita and age (the methodological details on the construction of the two-dimensional tensor product are reported in Appendix A).

To estimate the smooth functions $f_{j}(\cdot), f_{1 j}(\cdot), f_{2 j}(\cdot)$, and $f_{3 j}(\cdot)$, we use the regression spline approach (Wood 2006a). In particular, the smooth function for a generic covariate $x$ is approximated by a linear combination $\sum_{k=1}^{K_{j}} v_{j k} b_{k}\left(x_{j i}\right)$, where $b_{k}\left(x_{j i}\right)$ are the known (cubic) spline bases, $v_{j k}$ constitute the unknown regression parameters, and $K_{j}$ is the number of basis functions. The smooth terms are subject to identifiability centring constraints, such as $\sum_{i=1}^{n} f_{j}\left(x_{j i}\right)=0, \sum_{i=1}^{n} f_{1 j}\left(x_{j i}\right)=0, \sum_{i=1}^{n} f_{2 j}\left(x_{j i}\right)=0$, and $\sum_{i=1}^{n} f_{3 j}\left(x_{j i}\right)=0 \forall j$, where $n$ is the number of observations (Wood 2006a). If we apply classic maximum likelihood (ML) estimation, we can obtain smooth function estimates that are too rough. To overcome this drawback, we can use penalised ML estimation (Wood 2006a). Specifically, each smooth function has an associated penalty $\boldsymbol{v}_{j}^{\top} \mathbf{Q}_{j} \boldsymbol{v}_{j}$, where $\boldsymbol{v}_{j}^{\top}=\left(v_{j 1}, \ldots, v_{j K_{j}}\right)$ and 
$\mathbf{Q}_{j}$ is a positive semi-definite square matrix of known coefficients measuring the roughness of the $j$ th smooth component. Smoothing penalties are necessary to avoid overfitting during the parameter estimation process. For further details, see Wood (2006a).

From the estimated models, we are able to predict the transition probabilities from different states (employed, unemployed, and inactive). In the first step, we estimate the probabilities in the transition matrix (1) of the hierarchical structure by using Eq. (2):

$$
\begin{aligned}
& \hat{P} 02=\hat{P}\left(Y^{F} \in S_{1} / Y^{C}=0, \mathbf{x}\right) \\
& \hat{P} 12=\hat{P}\left(Y^{F} \in S_{1} / Y^{C}=1, \mathbf{x}\right) \\
& \hat{P} 20=\hat{P}\left(Y^{F} \in S_{1} / Y^{C}=2, \mathbf{x}\right) .
\end{aligned}
$$

In the second step, as the sum of each row in the transition matrix (1) is equal to 1 , the probabilities are obtained from Eqs. (2), (3), (4), (5), (6), (7), and (8):

$$
\begin{aligned}
& \hat{P} 01=\hat{P}\left(Y^{F}=1 / Y^{F} \in S_{2}, Y^{C}=0, \mathbf{x}\right)(1-\hat{P} 02) \\
& \hat{P} 10=\hat{P}\left(Y^{F}=0 / Y^{F} \in S_{2}, Y^{C}=1, \mathbf{x}\right)(1-\hat{P} 12) \\
& \hat{P} 21=\hat{P}\left(Y^{F}=1 / Y^{F} \in S_{2}, Y^{C}=2, \mathbf{x}\right)(1-\hat{P} 20) \\
& \hat{P} 00=(1-\hat{P} 01)(1-\hat{P} 02) \\
& \hat{P} 11=(1-\hat{P} 02)(1-\hat{P} 12) \\
& \hat{P} 22=(1-\hat{P} 21)(1-\hat{P} 20) .
\end{aligned}
$$

These tools can help policy-makers and practitioners generate ad hoc simulations of labour market transition probabilities.

\section{Data}

The estimation of labour market transition probabilities for the Italian case is based on longitudinal microdata from the ISTAT LFS. The longitudinal data provide information on individuals observed during two periods that are 12 months apart ( $1^{\circ}$ quarter of year $T$ and $1^{\circ}$ quarter of year $\left.T+1\right)$. As noted in the documentation provided by ISTAT, a limitation of the longitudinal microdata files is that they are by-products of the LFS and are thus not representative of the entire population. An individual interviewed for the first time in a municipality is not re-interviewed in that quarter of year $T+1$ if he/she has changed residences or moved abroad. It follows that, for a defined period of time, the longitudinal component does not represent the whole population but only of residents of the same municipality at both the beginning and the end of the period considered, i.e. the longitudinal population. In any case, as mentioned in Section 1, we are interested in the working age population that resides in the same region during the observation period.

The longitudinal microdata for Italy cover the period from 1993 to 2013. However, beginning in 2004, ISTAT made some important changes to both the classification of individual labour market status and the design of its survey. The surveys conducted during 
the 1993-2003 and 2004-2013 periods cannot be directly compared. Therefore, we have restricted our analysis to the 2004-2013 period (e.g. Fabrizi and Mussida 2009; Baussola and Mussida 2014).

The analysis has focused on the population of males and females from 18 to 74 years of age. Studies in the literature usually consider the working-age population to be between 15 and 64 years old. However, people have begin working past the typical retirement age (64 years old), and we have increased the upper limit of the age range to 74 years. Over the 2004-2005 and 2012-2013 periods, for each set of years considered, we examine more than 20,000 males and 20,000 females (see also Tables 5, 6 and 7 in Appendix B).

A possible limitation of the available data is that multiple labour market transitions may occur during the time span (12 months). In this regard, Baussola et al. (2015) have estimated labour market transitions in Italy by applying both the Markovian approach and the method proposed by Shimer (2012) to correct for multiple transitions. In comparing the results obtained from each approach, they find no significant differences.

\subsection{Some empirical evidence from labour market transitions}

We provide a descriptive time series analysis of transitions from one state to another in the Italian labour market over the observation period. The transition probability is computed by using the microdata described in the previous section. Moreover, we include some statistics on the control variables included in each model.

Transitions from the employed state: Figure 2 illustrates the probabilities of transitioning from the employed state to the unemployed (P01) and inactive (P02) states for both genders. Our initial inspection reveals an increase in $P 01$ for both genders after 20072008. One cause of this phenomenon is the negative impact of the recent global economic recession on the labour market. Females show a higher P02 than males, which reflects the organisational characteristics of Italian society in which females typically play an important role in child and family care (Theodossiou and Zangelidis 2009; Pacelli et al. 2013). From this perspective and consistent with similar studies, the probability of voluntary exit from the workforce is higher for women than for men, particularly among married women (e.g. Hersch and Stratton 1997; Keith and McWilliams 1999; Theodossiou 2002). Notably, we observe a decrease in the gender gap over time for those transitioning to the
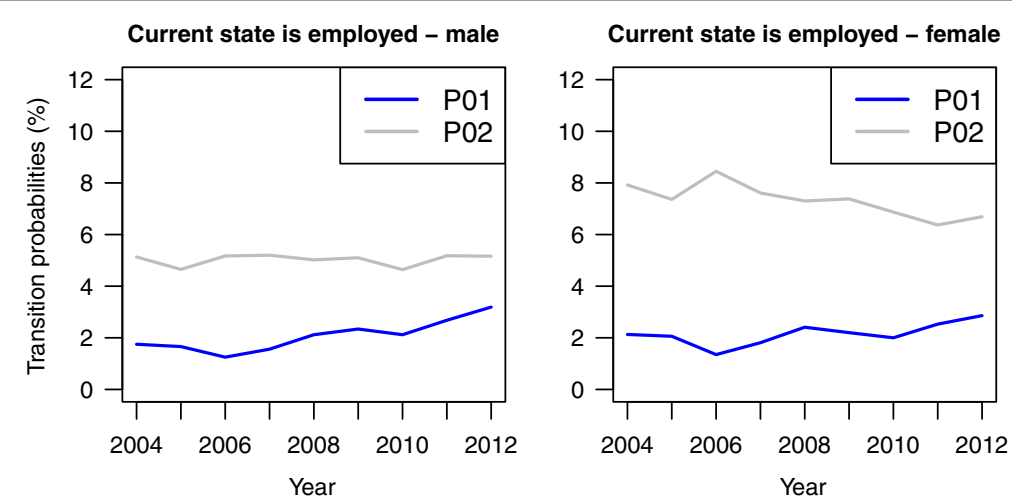

Fig. 2 Percentage of people who transitioned from the employed state to the unemployed state $(P 01)$ or from the employed state to the inactive state (P02). The year reported on the $x$-axis refers to the current state 
inactive state (P02). The negative effects of the recent recession have likely increased economic uncertainty in households, discouraging women from leaving their jobs because they must help support their families (e.g. Curci and Mariani 2013).

In Table 5 in the Appendix B, we report some descriptive statistics for the control variables for 2004 and 2012, while distinguishing between males and females. In Table 8 of the Appendix B, we report region-level GDP per capita (NUTS-2 level) for the same two points in time (2004 and 2012).

In comparing the descriptive statistics in the two point in time, we note an increasing share of workers from outside the 27 countries of the European Union (EU27, +4.6 percentage points over the study period). This growing presence of foreign workers has contributed to the re-composition of the labour market among Italian citizens, foreign EU27 workers, and foreign non-EU27 workers of both genders. We also note that the average number of years of education among employed workers (males and females) rose slightly from 2004 to 2012.

In terms of the composition of the sample for the type of employment, we note that half as many females as males are entrepreneurs. Among employed people of both genders, the percentage of people employed with permanent contracts is higher than $60 \%$. Another aspect of interest is the increase in the number of employed females in the service sector, as other sectors such as industry have suffered since the economic crisis. The distribution of employed workers by firm size reflects the Italian entrepreneurial structure, which is based on small- and medium-sized enterprises. For each interviewee employed at time $T$, we have associated the GDP per capita of the region of residence. This is the maximum disaggregation possible for a link between macro- and microdata. The data reported in Table 8 in Appendix B show the structural nature of regional differences in GDP per capita. Specifically, we observe that the highest levels are registered in the northwest, while the lowest levels are in the southern region and in the islands.

Transitions from the unemployed state: Regarding unemployed workers, from a descriptive analysis, we have found that the sample of units includes people up to 66 years old. Thus, our analysis will be restricted to the sample of unemployed individuals between 18 and 66 years old. In Fig. 3, we observe a decreasing trend in $P 10$ for the male population

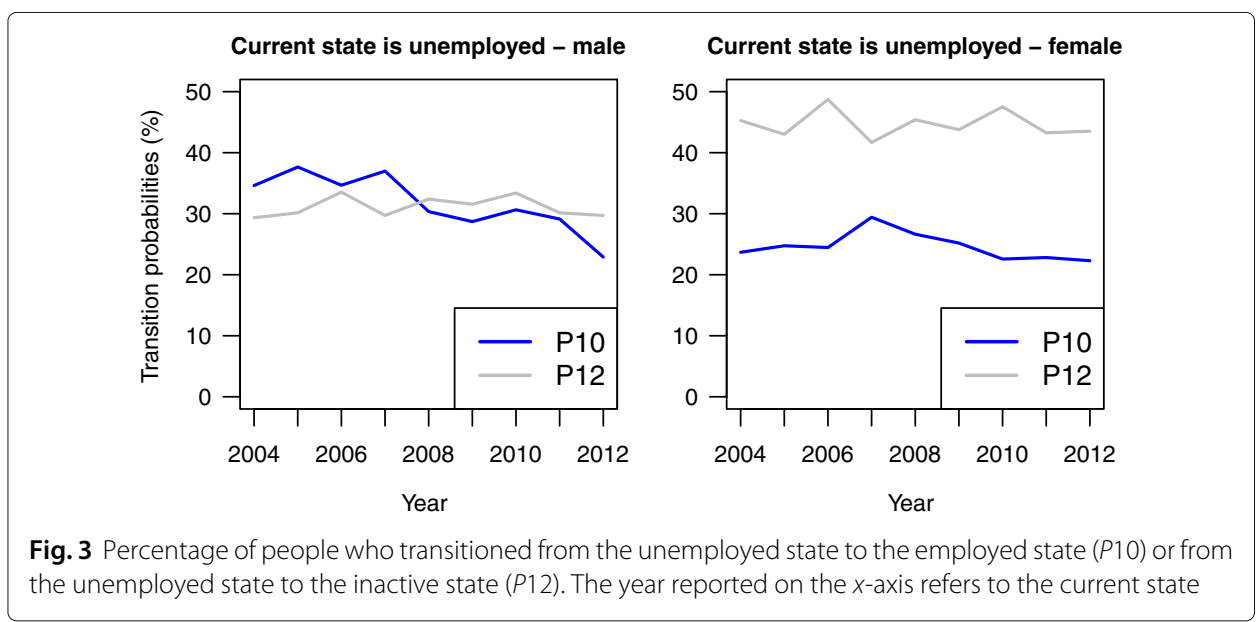


and a reduction in the historical gap between genders. This pattern reflects one negative effect of the great economic recession. The $P 12$ pattern shows higher values for females than for males (a difference of more than 10 percentage points), which remains stable during the observed period. The difficulty of finding a job can discourage female workers. As a consequence, they are likely to stop actively looking for a job and to devote their time to family care (see also Curci and Mariani 2013).

From Fig. 3, we can deduce an increased probability of remaining unemployed (P11). The prolonged weak economy experienced by Italy in recent years has undoubtedly hampered the search for initial employment or re-employment.

In Table 6 in the Appendix B, we report some descriptive statistics for the selected control variables at two points in time (2004 and 2012, the beginning and the end of the observation period), while distinguishing between males and females. In addition to factors associated with citizenship, education, age of the individual, and share of children in the household, we have taken into account previous labour experience and information about the duration of the job search. In the sample of unemployed workers considered for our analysis, approximately $80 \%$ of males and females in the sample reported previous labour experience.

As regards the duration of the job search, long-term unemployment is a crucial labour market indicator that is constantly monitored by policy-makers. Organisations (such as Eurostat or the OECD) provide official statistics on the long-term unemployment rate (12 months or longer). However, using microdata, it is possible to disaggregate the information on the duration of the job search into several sub-periods: up to 6 months of unemployment (short term), between 7 and 12 months (medium term), between 13 and 24 months (long term), and over 25 months (very long term). We observe that in 2012, long-term unemployment (over 12 months) affected approximately 43 and $40 \%$ of male and female unemployed workers, respectively. This indicator is in line with official statistics for 2012 that indicate a percentage of long-term unemployed workers of approximately $52 \%$ in Italy. Differences in the magnitude of the indicator can be reasonably attributed to the characteristics of the selected longitudinal sample, as discussed in previous sections.

Transitions from the inactive state: The inactive category includes individuals who are not in the labour force, such as students or housewives. They receive neither income from work nor unemployment benefits. The retired are not included in our analysis. Among the inactive are the discouraged people who, although able to work, are not actively seeking a job because they believe they cannot find one. Discouragement arises in instances of longterm unemployment or when the worker believes that the cost of finding a job is greater than the expected return of the search. This phenomenon is more likely to occur during periods of economic uncertainty than during periods of economic expansion (Curci and Mariani 2013).

Figure 4 shows a decrease in $P 20$ over the last years. This phenomenon is particularly prominent in the male population during the economic recession (post 2008). Nevertheless, inactive men are twice as likely as women to find a job. Extending the analysis to the spatial level, Curci and Mariani (2013) observe that females in southern Italy have lower $P 20$ values, which are attributed to family care and to the absence of policies that actively seek to create work-life balance. 

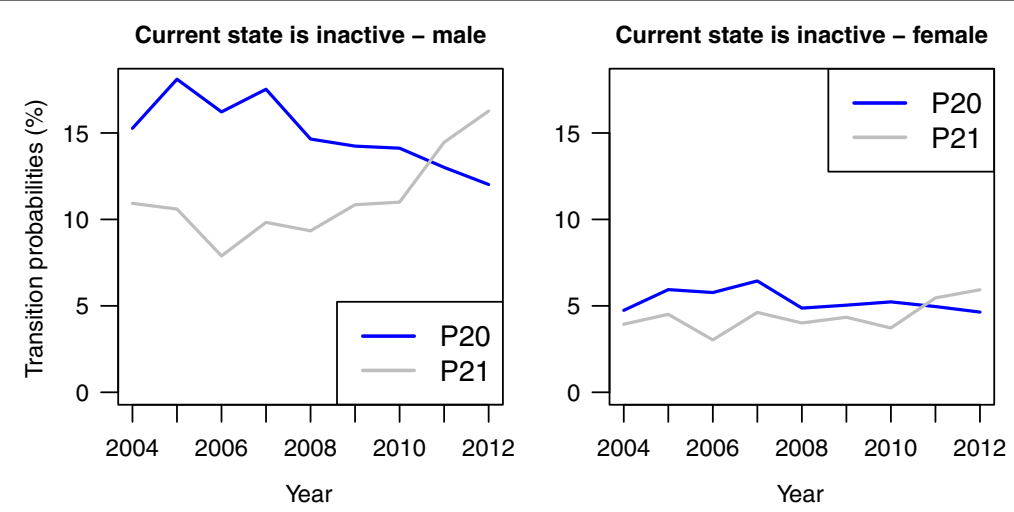

Fig. 4 The percentage of people who have transitioned from the inactive state to the employed state (P20) or from the inactive state to the unemployed state (P21). The year reported on the $x$-axis refers to the current state

While the sample of inactive females is characterised by a high prevalence of housewives, the sample of males consists primarily of students (Table 7 in the Appendix B). Therefore, the observed increase in $P 21$ for males can be explained in part by the difficulties that young people encounter in transitioning from school to work. Such issues are exacerbated by persistently weak macroeconomic growth since the beginning of the great recession in 2007-2008 (e.g. Pastore 2012).

\section{Results}

In this section, we present the results of the estimated flexible hierarchical logit models with interaction effects. Specifically, we discuss some evidence obtained from the interaction between age and region-level GDP per capita during the period of observation.

To provide a model comparison, we have also studied labour market transitions by applying a traditional parametric MNL model. Importantly, we note that the use of a parametric MNL approach rather than a flexible hierarchical logit model leads to predicted probabilities that can be either underestimated or overestimated under the assumption of linear dependence between the continuous covariates of interest and the outcomes (to save space, these results are not presented but are available upon request). Such a situation is not ideal for capturing and uncovering patterns in the focal relationship that are not known a priori. This evidence supports the use a flexible modelling approach to minimise specification error by allowing the data to determine whether the relationship under investigation is linear or non-linear. Hence, a flexible approach aims to improve the interpretation of the results and the process of analysis. The models were estimated using the R package 'mgcv'.

For each labour market transition, we report two types of results: in Figs. 5, 6 and 7, we display the probabilistic pattern associated with varying values of several combinations of worker age and region-level GDP per capita ${ }^{2}$. These figures were produced using vis.gam () in mgcv. In Tables 1, 2 and 3, we instead report the marginal effects (MEs) of the control variables. The information in terms of linear predictors (i.e. coefficients and plot of smooth functions) is available upon request. 

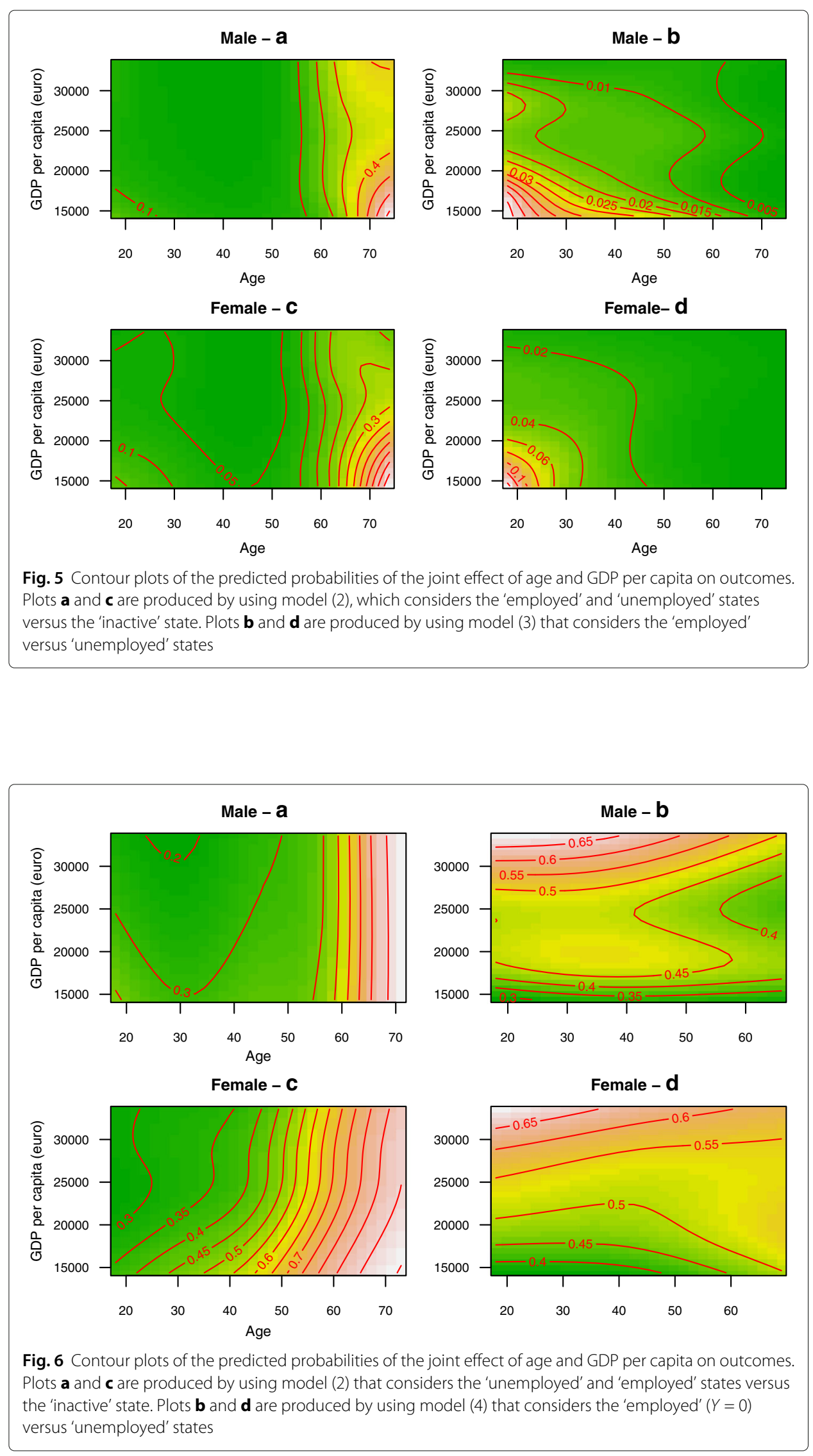


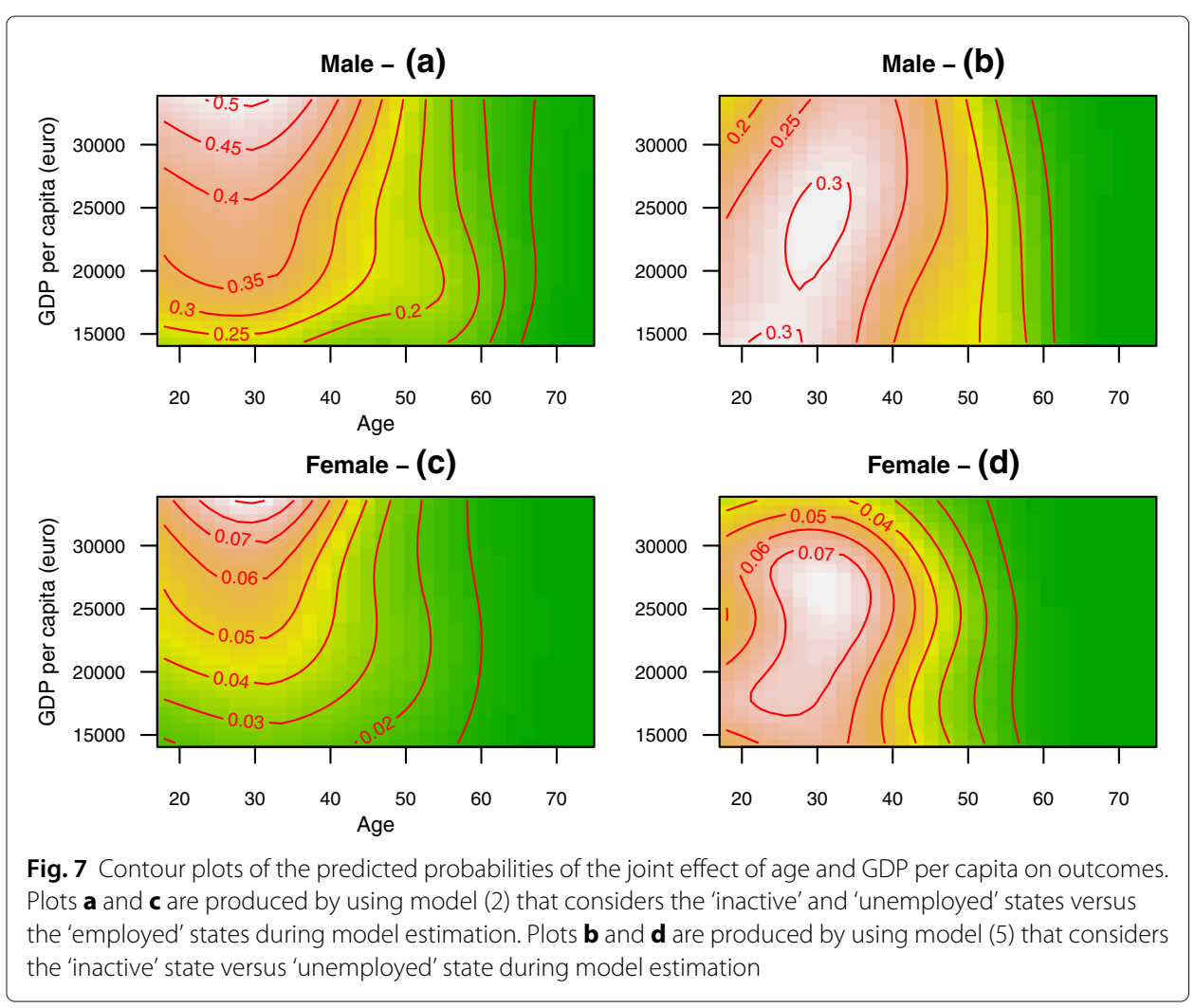

\subsection{Transitions from employment}

Figure 5 displays the predicted transition probabilities from the employed state obtained by using Eqs. (2) and (3), with an emphasis on the interaction between age and regional GDP per capita.

From plots (a) and (c), we observe that the probability of exiting the labour force increases progressively for older people (more than 50 years old) independently of the level of GDP per capita. This phenomenon is directly related to progressive exit from the labour force due to retirement (or early retirement).

Plots (b) and (d) show the predicted probabilities from the employed state to the unemployed state for males and females, respectively. We observe that the probability of job loss is highest among young people living in a context of less favourable GDP per capita (in particular, when GDP per capita is below 20,000 euros). As we can observe from Table 8 in the Appendix B, these areas are located mainly in southern Italy and in the main islands.

This finding is consistent with official statistics that register higher levels of youth unemployment in such areas of the country. The literature generally acknowledges that the youngest members of the labour force are more likely to be employed with temporary contracts, making them more sensitive to job losses-particularly during periods of recession-than older members of the workforce (e.g. Zanin 2014). Despite policies aimed at promoting youth employment, when an individual lives in an area with a low GDP per capita, the phenomenon of job loss can be exacerbated by poor labour opportunities. 
Table 1 Model (2) considers the 'employed' and 'unemployed' states versus the 'inactive' state. Model (3) considers the 'employed' state versus the 'unemployed' state. The ME for a continuous covariate is computed as the change in the probability from the mean value after an increase of one standard deviation in the variable of interest, with all other variables held at their observed values. The ME for a categorical variable is measured as the change in the probability from 0 to 1 , with all other variables held at their observed values

\begin{tabular}{|c|c|c|c|c|}
\hline \multirow[b]{2}{*}{ Variables } & \multicolumn{2}{|l|}{ Men } & \multicolumn{2}{|l|}{ Women } \\
\hline & Model (2) & Model (3) & Model (2) & Model (3) \\
\hline \multicolumn{5}{|l|}{ Citizenship } \\
\hline Italian & - & - & - & - \\
\hline Foreign EU27 & 0.007 & $0.016^{* *}$ & -0.003 & $0.017^{* *}$ \\
\hline Foreign non-EU27 & -0.004 & $0.017^{* *}$ & 0.001 & $0.013^{* *}$ \\
\hline \multicolumn{5}{|l|}{ Socio-demographic factors } \\
\hline Years of education & $-0.009^{* *}$ & $-0.003^{* *}$ & $-0.008^{* *}$ & $-0.006^{* *}$ \\
\hline Share of children in the household & $-0.009^{* *}$ & $-0.003^{* *}$ & $0.002^{* *}$ & $-0.003^{*}$ \\
\hline \multicolumn{5}{|l|}{ Type of employment } \\
\hline Employed (permanent contract) & - & - & - & - \\
\hline Employed (fixed-term contract) & $0.061^{* *}$ & $0.072^{* *}$ & $0.079^{* *}$ & $0.056^{* *}$ \\
\hline Self-employed (collabouration) & $0.013^{* *}$ & 0.006 & $0.018^{* *}$ & 0.009 \\
\hline Self-employed (entrepreneur) & $-0.034^{* *}$ & $-0.021^{* *}$ & $-0.022^{* *}$ & $-0.013^{* *}$ \\
\hline Self-employed (freelancer) & $-0.037^{* *}$ & $-0.022^{* *}$ & $-0.030^{* *}$ & $-0.015^{* *}$ \\
\hline Self-employed (co-adjuvant of family business) & $0.030^{* *}$ & -0.001 & $0.039^{* *}$ & $-0.011^{* *}$ \\
\hline \multicolumn{5}{|l|}{ Sector of employment } \\
\hline Agriculture & $0.008^{* *}$ & $-0.006^{* *}$ & $0.060^{* *}$ & -0.002 \\
\hline Buildings & $0.014^{* *}$ & $0.013^{* *}$ & $0.034^{* *}$ & $0.021^{* *}$ \\
\hline Industry & 0.002 & $0.003^{* *}$ & $0.020^{* *}$ & $0.008^{* *}$ \\
\hline Commerce & $-0.008^{* *}$ & 0.001 & $-0.008^{* *}$ & 0.002 \\
\hline Services & - & - & - & - \\
\hline \multicolumn{5}{|l|}{ Size of the firm (num. of employees) } \\
\hline No employee & $0.037^{* *}$ & $0.050^{* *}$ & $0.072^{* *}$ & $0.043^{* *}$ \\
\hline Up to 10 employees & $0.004^{* *}$ & $0.007^{* *}$ & $0.024^{* *}$ & $0.015^{* *}$ \\
\hline From 11 to 49 employees & - & - & - & - \\
\hline From 50 to 250 employees & $-0.004^{* *}$ & $-0.007^{* *}$ & $-0.006^{* *}$ & $-0.006^{* *}$ \\
\hline More than 250 employees & -0.003 & $-0.010^{* *}$ & -0.004 & $-0.006^{* *}$ \\
\hline Number of observations & 138,282 & 131,351 & 95,208 & 88,213 \\
\hline UBRE & -0.673 & -0.819 & -0.539 & -0.807 \\
\hline Deviance explained & $17.90 \%$ & $12.50 \%$ & $12.40 \%$ & $12.50 \%$ \\
\hline
\end{tabular}

**P $<0.05$

$* P<0.1$

Table 1 reports the MEs of the remaining covariates included in models (2) (second and fourth columns) and (3) (third and fifth columns). From Eq. (2), the results in terms of linear predictor show non-linear negative dependence of education on the transition from employment to inactivity (the graphical pattern is available upon request). Considering a mean value of 11-12 years of education (Table 5 in the Appendix B), in terms of MEs, an increase of one standard deviation reduces the probability of exiting the labour market by 0.9 and 0.8 percentage points for males and females, respectively. This finding is consistent with similar studies that support the important role of education in reducing transitions to the unemployed state and to the inactive state (e.g. Baussola and Mussida 2014; IMF 2014, p. 41). 
Table 2 Model (2) considers the 'unemployed' and 'employed' states versus the 'inactive' state. Model (4) considers the 'employed' state versus the 'unemployed' state. The ME for a continuous covariate is computed as the change in the probability from the mean value after an increase of one standard deviation in the variable $X$ of interest, with all other variables held at their observed values. The ME for a categorical variable is measured as the change in the probability from 0 to 1 , with all other variables held at their observed values

\begin{tabular}{|c|c|c|c|c|}
\hline \multirow[b]{2}{*}{ Variables } & \multicolumn{2}{|l|}{ Men } & \multicolumn{2}{|l|}{ Women } \\
\hline & Model (2) & Model (4) & Model (2) & Model (4) \\
\hline \multicolumn{5}{|l|}{ Citizenship } \\
\hline Italian & - & - & - & - \\
\hline Foreign EU27 & -0.034 & -0.012 & $-0.067^{* *}$ & $0.025^{* *}$ \\
\hline Foreign non-EU27 & $-0.048^{* *}$ & $-0.107^{* *}$ & -0.010 & -0.071 \\
\hline \multicolumn{5}{|l|}{ Socio-demographic factors } \\
\hline Years of education & $0.012^{* *}$ & $0.031^{* *}$ & $-0.039^{* *}$ & $0.068^{* *}$ \\
\hline Share of children in the household & $-0.029^{* *}$ & $0.028^{* *}$ & $0.031^{* *}$ & -0.008 \\
\hline \multicolumn{5}{|l|}{ Labour experience } \\
\hline Yes & - & - & - & - \\
\hline No & $0.056^{* *}$ & $-0.038^{* *}$ & $0.092^{* *}$ & $-0.073^{* *}$ \\
\hline \multicolumn{5}{|l|}{ Duration of job search } \\
\hline Up to 6 months & - & - & - & - \\
\hline Between 7 and 12 months & 0.003 & $-0.080^{* *}$ & $0.048^{* *}$ & $-0.083^{* *}$ \\
\hline Between 13 and 24 months & 0.015 & $-0.157^{* *}$ & 0.020 & $-0.130^{* *}$ \\
\hline Greater than 25 months & $0.023^{*}$ & $-0.206^{* *}$ & $0.059^{* *}$ & $-0.203^{* *}$ \\
\hline Unknown & 0.034 & $-0.131^{* *}$ & $0.055^{*}$ & $-0.098^{* *}$ \\
\hline Number of observations & 10,079 & 6953 & 10,342 & 5717 \\
\hline UBRE & 0.202 & 0.312 & 0.305 & 0.292 \\
\hline Deviance explained & $3.31 \%$ & $5.20 \%$ & $5.40 \%$ & $6.39 \%$ \\
\hline
\end{tabular}

Opposing gender effects on the transition probability are observed when there are children in the household. Although a negative effect on the probability of exiting the labour force is found for employed males, a positive effect is observed for females. As acknowledged in the literature, males are less likely to leave a job because they must support their household, whereas females are more likely to spontaneously leave a job to dedicate their time to caring for their children (see also Theodossiou and Zangelidis 2009).

Examining the type of occupation, we find that the probability that an individual employed under a temporary contract exits the labour force in the next 12 months is between 6.1 and 7.9 percentage points higher for males and females, respectively, than for an individual employed under a permanent contract. By contrast, self-employed entrepreneurs ( -3.4 and -2.2 percentage points for males and females, respectively) and freelancers ( -3.7 and -3.0 percentage points for males and females, respectively) are less likely to exit the labour force. Based on similar studies of Italy, we have included the size of the firm that employs the individual in the models. We find a higher probability of exit over the next 12 months for individuals employed at smaller firms compared to people employed by firms in the size reference category (from 11 to 49 employees). Considering that most of the Italian economy is based on small businesses, this evidence should capture the attention of policy-makers. 
Table 3 Model (2) considers the 'inactive' and 'unemployed' state versus the 'employed' state. Model (5) considers the 'inactive' state versus the 'unemployed' state. The ME for a continuous covariate is computed as the change in the probability from the mean value after an increase of one standard deviation in the variable $X$ of interest, with all other variables held at their observed values. The ME for a categorical variable is measured as the change in the probability from 0 to 1 , with all other variables held at their observed values

\begin{tabular}{|c|c|c|c|c|}
\hline \multirow[b]{2}{*}{ Variables } & \multicolumn{2}{|l|}{ Men } & \multicolumn{2}{|l|}{ Women } \\
\hline & Model (2) & Model (5) & Model (2) & Model (5) \\
\hline \multicolumn{5}{|l|}{ Citizenship } \\
\hline Italian & - & - & - & - \\
\hline Foreign EU27 & $0.043^{* *}$ & 0.010 & $0.008^{* *}$ & $0.012^{* *}$ \\
\hline Foreign non-EU27 & 0.003 & 0.003 & $-0.016^{*}$ & $0.014^{* *}$ \\
\hline \multicolumn{5}{|l|}{ Socio-demographic factors } \\
\hline Years of education & $0.001^{* *}$ & $-0.022^{* *}$ & $0.010^{* *}$ & $0.001^{* *}$ \\
\hline Share of children in the household & $0.014^{* *}$ & $0.005^{* *}$ & -0.001 & $-0.006^{* *}$ \\
\hline \multicolumn{5}{|l|}{ Labour experience } \\
\hline Yes & - & - & - & - \\
\hline No & $-0.062^{* *}$ & $-0.052^{* *}$ & $-0.029^{* *}$ & $-0.017^{* *}$ \\
\hline \multicolumn{5}{|c|}{ Status of the individual out of labour force } \\
\hline Student & $-0.116^{* *}$ & $-0.144^{* *}$ & $-0.034^{* *}$ & $-0.044^{* *}$ \\
\hline Housewife & - & - & $-0.063^{* *}$ & $-0.066^{* *}$ \\
\hline Invalid & $-0.149^{* *}$ & $-0.158^{* *}$ & $-0.051^{* *}$ & $-0.049^{* *}$ \\
\hline In other condition & - & - & - & - \\
\hline Number of observations & 28,629 & 24,401 & 105,136 & 99,547 \\
\hline UBRE & -0.261 & -0.345 & -0.658 & -0.700 \\
\hline Deviance explained & $12.00 \%$ & $15.70 \%$ & $17.70 \%$ & $19.70 \%$ \\
\hline
\end{tabular}

From the estimates obtained by Eq. (3) (third and fifth columns), we find that the probability of becoming unemployed from the employed state increases for people who are foreign citizens, who are on fixed-term contracts, who work in the industrial or construction sectors (which are more sensitive to business cycles), and who are employed by small firms. Transition probabilities are lower for people who work in the agriculture sector, who are self-employed, and who are employed by a large firm.

\subsection{Transitions from unemployment}

Figure 6 displays the predicted probabilities of transitioning from the unemployed state obtained from Eqs. (2) and (4), which emphasise the interaction between age and regional GDP per capita.

Plots (a) and (c) show the predicted probabilities of exiting the labour force in the next 12 months for unemployed males and females. For males, the highest probability of exiting the labour force occurs when an individual is over 50 years old, regardless the regional GDP per capita level. These results may be due to a number of factors. For example, among older people who experience difficulty finding a new job, exiting the labour force likely occurs as a result of discouragement. If so, this issue should be a priority on the political agenda of the welfare system. This is because unemployment can affect poverty 
in old age, especially among people who have not yet met all requirements to receive a pension (see also Pestieau and Racionero 2016).

For females, especially among the youngest workers (i.e. up to 35-40 years old) living in areas with low GDP per capita, the predicted probabilities of exit from the labour force are higher than they would be with higher GDP per capita. For example, for a 35-yearold female who lives in a region with a GDP per capita of approximately 15,000 euros, the predicted probability of exiting the labour force is approximately 0.5 . For a female in the same age cohort but who lives in a region with a GDP per capita of approximately 30,000 euros, the predicted probability of exit from the labour force decreases to 0.35 . This pattern suggests difference in labour market opportunities based on the characteristics of the local economy, ceteris paribus.

Plots (b) and (d) show the transition probabilities from unemployment to employment for males and females, respectively. For both genders, the highest predicted probabilities of transition are among workers up to 35-40 years old who live in areas with the highest GDP per capita levels (in particular, when GDP per capita is higher than 25,000 euros). The gap in the predicted probability-compared to individuals of the same age living in areas with a GDP per capita below 25,000 euros-is approximately $0.2-0.3$ points lower. This pattern should alarm policy-makers, since it signals the presence of crucial issues in the labour market and differences in job opportunities without moving the residence. In recent years, policy-makers have initiated several efforts (e.g. decreased labour taxes, new regulations) geared towards improving the entry of young people into the labour market and reducing the gap in the unemployment rate between younger and older workers. Young people represent an appealing reservoir from which firms can look for the skills and knowledge required to be innovative and competitive in both local and global markets. In this regard, Ouimet and Zarutskie (2013) provide evidence that young employees with more recent education have appealing technical skills that can enter into the process of developing new products or establishing new methods of production. Thereby, they can function as the 'engine' of competitiveness and firm and local economic growth.

Our findings yield interesting insights not only for issues associated with young workers but also for older worker who are not yet eligible for retirement. As discussed in the literature, potential mismatches in productivity, less-updated skills, and seniority-based wages represent crucial factors that lead employers to think that older people who are searching for jobs are less incentivised to work (e.g. Buyse et al. 2013; Eichhorst et al. 2013; IMF, 2014, p.41; Baussola and Mussida 2014; Mazzola et al. 2015). An International Monetary Fund (2014, p. 41) report mentions possible action strategies to reduce barriers to re-entry into the labour market for older workers, including implementing anti-discrimination standards, reducing labour taxes, and investing in continuing education during working age. Improving job opportunities can have positive effects on economic factors, such as consumption and savings, and can reduce the psychological distress associated with being unemployed; such improvements can improve the quality of life of the population (e.g. Blundell et al. 1997; Flint et al. 2013).

Table 2 reports the MEs of the remaining covariates included in models (2) (second and fourth columns) and (4) (third and fifth columns). As regards the control variables, we found that a lack of labour experience significantly affects transition probabilities from the unemployed state. Specifically, we estimate that for people without labour experience, the probability of exiting the labour force increases by 9.2 and 5.6 percentage points for 
females and males, respectively, compared to the reference category (i.e. workers with labour experience). By contrast, we estimated that the transition probability from unemployment to employment decreases by 7.3 and 3.8 percentage points for females and males with no labour experience, respectively.

As suggested in the literature (see Section 1), the number of months an unemployed worker has spent in searching for a job is an important factor that affects the transition probabilities. In our case, the variable can only be considered a proxy for the duration of the search due to the limitation of the measure. Specifically, during the interview, each unemployed individual was asked to indicate the number of months he/she has spent searching for a job. In analysing the distribution of answers, we note peaks in fixed periods (e.g. 6, 12, 18, and 24 months) that can be attributed to a telescopic effect of remembering the exact month in which they began looking for a job (see also Section 3.1 for the definition of the categorical variable). In light of this, caution should be exercised in interpreting the results. Moreover, a duration analysis would be the best method of studying the dependence between the duration of unemployment and the transition probabilities. However, this topic was not the primary focus of our study. We can only observe that there is a negative association between the duration of a job search and finding a job for workers of both genders.

Another finding of interest is that the presence of children in the household provides an incentive for unemployed females, and a disincentive for unemployed males, to exit the labour force.

\subsection{Transitions from the inactive state}

Figure 7 displays the predicted transition probabilities from the inactive state obtained from Eqs. (2) and (5), with an emphasis on the interaction between age and region-level GDP per capita during the period of observation.

Plots (a) and (c) show the predicted probabilities that males and females who are inactive at time $T$ earn income from labour in the next 12 months, that is, that they find a job. For both genders, we observe the highest transition probabilities for workers up to 30-35 years old, particularly when people live in regions with a GDP per capita higher than 25,000 euros. For example, for young people between 20 and 30 years old, the probability of becoming labour income earners with a regional GDP per capita above 30,000 euros is approximately 0.5 and 0.08 for males and females, respectively. The probabilities decrease to 0.25 and 0.02 for males and females, respectively, when GDP per capita is approximately 15,000 euros. Differences in the magnitude of the probabilities can be attributed to the composition of the sample. As described in Section 3.1, the sample of inactive females is mainly composed of housewife, while inactive males are mainly students.

Plots (b) and (d) show the predicted probabilities that inactive males and females become unemployed in the next 12 months. Hence, they start to search for a job. As for plots (a) and (c), we observe that the highest probabilities of exit from inactivity to searching for a job are observed for males and females up to 40 years old. Interestingly, we note marginal differences in the predicted probability at varying levels of GDP per capita. In any case, as described for plots (a) and (c), the magnitudes of the predicted probabilities reported in the contour plot reflect the composition of the sample (see Table 7 in the Appendix B). 
Table 3 reports the MEs of the remaining covariates included in models (2) (second and fourth columns) and (5) (third and fifth columns). Consistent with Baussola and Mussida (2014), we find that inactive foreign workers from countries within the EU27 have a higher likelihood of becoming employed than do Italian citizens ( 4.3 and 0.7 percentage points for males and females, respectively).

A lack of labour experience is observed to be a barrier to becoming a labour income earner (MEs equal to -6.2 and -0.3 percentage points for males and females, respectively) and provides a disincentive to search for a job (MEs equal to -5.2 and -1.7 percentage points for males and females, respectively). In investigating the status of individuals, the inactive groups with the weakest incentives to become employed include males with disabilities and housewives.

\subsection{The predicted probabilities of the labour market transition matrix with varying age and levels of regional GDP per capita: an empirical exercise}

As presented in Section 2.2, after model estimation, the computation of the predicted probabilities at varying ages and levels of regional GDP per capita following the structure of the transition matrix in Section 2.1 requires the notation from Eqs. (6)-(14). This specific output is not reported in Sections 4.1, 4.2, and 4.3. To achieve our aims, we first define some individual reference profiles, as reported in Table 4. This is one possible empirical exercise that can be useful to both policy-makers and economic agents. In other words, we obtain the predicted probabilities of transitioning to and from different labour market states (employed, unemployed, inactive) at varying ages (from 20 to 74 years old) and levels of GDP per capita (from 14,000 to 33,500 euros), ceteris paribus (i.e. in terms of control variables). The results are graphically represented in Figs. 8 and 9.

The plots display the predicted probabilities of labour market transitions by age and level of regional GDP per capita, ceteris paribus. We start by providing some empirical evidence obtained from the simulation of the probability of an event of transition from

Table 4 Profile of individuals at time $T$

\begin{tabular}{|c|c|c|}
\hline \multicolumn{2}{|l|}{ In labour force } & \multirow{2}{*}{$\begin{array}{l}\text { Out of labour force } \\
\text { Inactive }\end{array}$} \\
\hline Employed & Unemployed & \\
\hline \multicolumn{3}{|l|}{ Socio-demographic factors } \\
\hline Age: from 20 to 74 years old & $\begin{array}{l}\text { Age: from } 20 \text { to } 74 \text { years } \\
\text { old }\end{array}$ & $\begin{array}{l}\text { Age: from } 20 \text { to } 74 \text { years } \\
\text { old }\end{array}$ \\
\hline Education: 13 years & Education: 13 years & Education: 13 years \\
\hline Share of children in the household: 0 & $\begin{array}{l}\text { Share of children in the } \\
\text { household: } 0\end{array}$ & $\begin{array}{l}\text { Share of children in the } \\
\text { household: } 0\end{array}$ \\
\hline Citizenship: Italian & Citizenship: Italian & Citizenship: Italian \\
\hline \multicolumn{3}{|l|}{ Conditions of the individual in/out of labour force } \\
\hline Employed: fixed-term contract & Labour experience: yes & Labour experience: yes \\
\hline Size of the firm: up to 10 employees & $\begin{array}{l}\text { Duration of job search: Up } \\
\text { to } 6 \text { months }\end{array}$ & $\begin{array}{l}\text { Status out of labour force: } \\
\text { in other condition }\end{array}$ \\
\hline \multicolumn{3}{|l|}{ Sector of employment: services } \\
\hline \multicolumn{3}{|l|}{ Economics } \\
\hline GDP per capita: from 14,000 to 33,500 euros & $\begin{array}{l}\text { GDP per capita: from } \\
14,000 \text { to } 33,500 \text { euros }\end{array}$ & $\begin{array}{l}\text { GDP per capita: from } \\
14,000 \text { to } 33,500 \text { euros }\end{array}$ \\
\hline
\end{tabular}




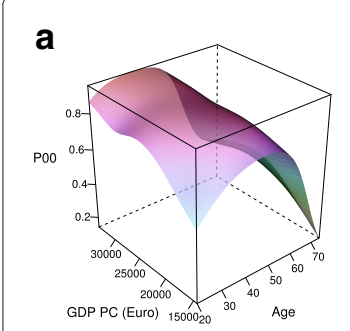

Employed vs Employed

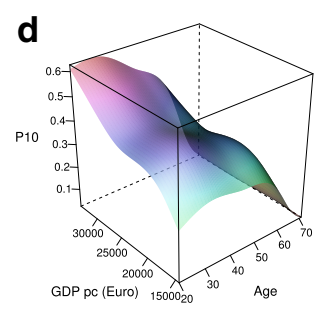

Unemployed vs Employed

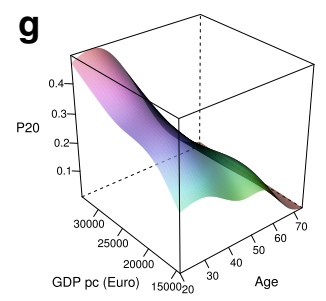

Inactive vs Employed

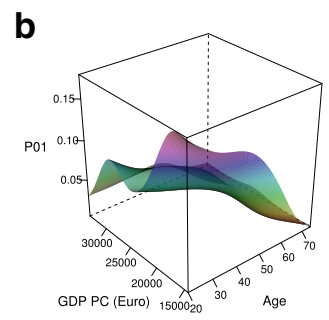

Employed vs Unemployed

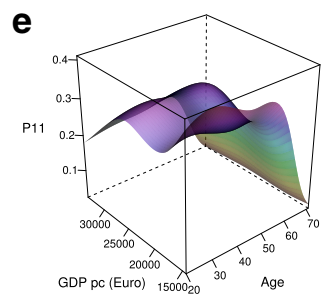

Unemployed vs Unemployed

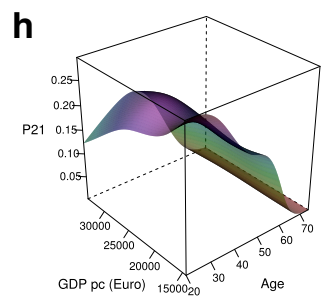

Inactive vs Unemployed

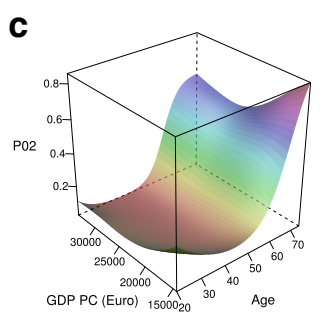

Employed vs Inactive

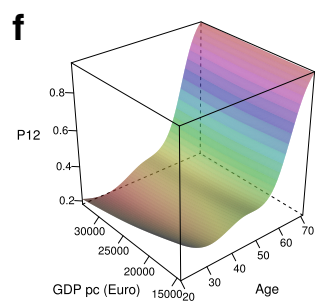

Unemployed vs Inactive

i

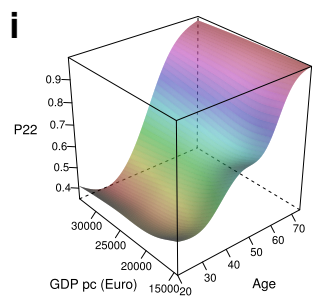

Inactive vs Inactive

Fig. 8 Three-dimensional plots of the predicted transition probabilities in the labour market for males by age $c$ ohort and GDP per capita in euros. a Employed versus employed. b Employed versus unemployed. c Employed versus inactive. d Unemployed versus employed. e Unemployed versus unemployed. f Unemployed versus inactive. $\mathbf{g}$ Inactive versus employed. $\mathbf{h}$ Inactive versus unemployed. $\mathbf{i}$ Inactive versus inactive

the employed state (first rows of Figs. 8 and 9 for males and females, respectively). For example, we observe that for a young male (20-30 years old) with a high school diploma, without children in the household and employed with a fixed-term contract in a small firm in the service sector, the probability that he remains employed in the next 12 months when residing in a region with a medium-high GDP per capita (more than 25,000 euros) is two times higher than that for individuals residing in a region with a low GDP per capita (less than 15-20,000 euros). This gap is slightly greater for females.

Additionally, we observe a higher probability of transitioning from employment to unemployment for workers of both genders residing in the most disadvantaged regions in terms of GDP per capita (second plot of the first rows of Figs. 8 and 9) compared to people who live in the richest areas. We also highlight how the transition from employment to unemployment can be crucial for people who are older-especially for males from 30 to 50 years old-and who reside in less-rich areas of the country. For males in these age cohorts and those who reside in the poorest regions, the probability of transitioning to unemployment can be up to two or three times higher than that for unemployed workers who live in wealthier areas. 


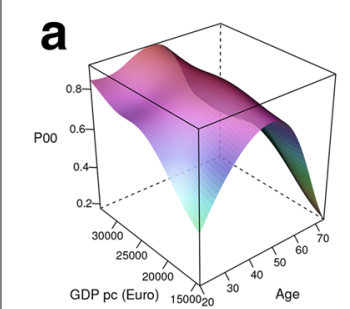

Employed vs Employed

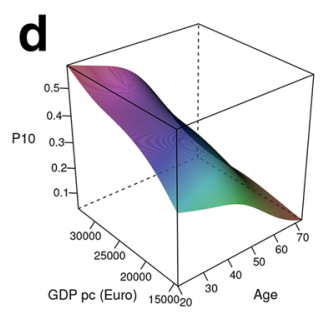

Unemployed vs Employed

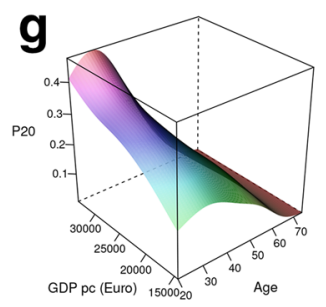

Inactive vs Employed

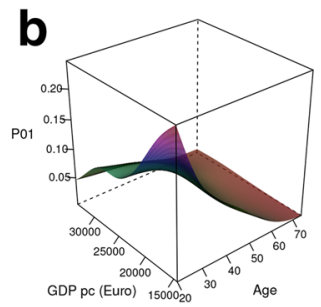

Employed vs Unemployed

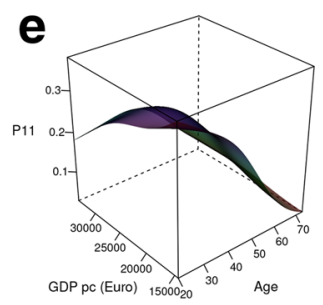

Unemployed vs Unemployed

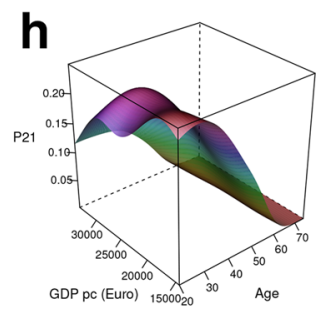

Inactive vs Unemployed

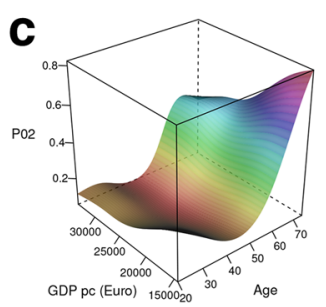

Employed vs Inactive

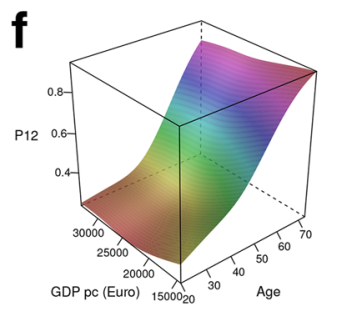

Unemployed vs Inactive

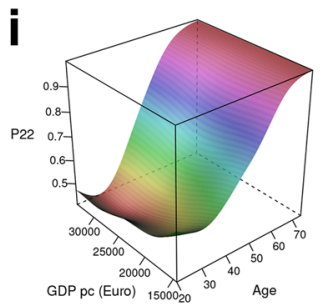

Inactive vs Inactive

Fig. 9 Three-dimensional plots of the predicted transition probabilities in the labour market for females by age cohort and GDP per capita in euros. a Employed versus employed. b Employed versus unemployed. c Employed versus inactive. d Unemployed versus employed. e Unemployed versus unemployed. f Unemployed versus inactive. $\mathbf{g}$ Inactive versus employed. $\mathbf{h}$ Inactive versus unemployed. i Inactive versus inactive

As regards the transition from employment to inactivity, it is interesting to note the decrease in the magnitude of the probability among older workers (especially for females more than 60 years old) residing in regions with low GDP per capita (below 20,000 euros) rather than in regions with the highest GDP per capita (greater than 25,000 euros). The gap is approximately 20 and 10 percentage points for females and males, respectively.

The second rows of Figs. 8 and 9 report the probability of a transition from the unemployed state for males and females. For a young male (20-30 years old) with a high school diploma, who has been unemployed for a few months (up to 6 months), and who has labour experience, residing in a region with a medium-high GDP per capita (more than 30,000 euros) has a probability of transitioning from unemployment to employment in the next 12 months that is three times higher than that for individuals who reside in a region with a low GDP per capita (less than 15-20,000 euros). This gap is very similar for females (first plot of the second row of Fig. 9). Interestingly, the probability of re-entry into the labour market decreases with age. Additionally, for older workers, we note smaller gaps in the transition probabilities by the level of GDP per capita.

The third plot of the second rows of Figs. 8 and 9 indicates that the probability of transitioning from unemployment to inactivity increases with age, a change that occurs earlier for females than for males (see also Section 4.2). 
The third rows of Figs. 8 and 9 report the probabilities of transitioning from the inactive state for males and females, respectively. For inactive young males and females with high school diplomas, at least one labour experience, and no children in the household, we note important differences in the predicted probability of transitioning from inactivity (out of the labour force and non-labour income earner) to employment (labour income earner) based on the levels of GDP per capita. Specifically, when an inactive individual resides in a region with a medium-high GDP per capita (more than 25,000 euros), the probability of becoming employed is approximately two times higher than that for an individual who resides in a region with a low GDP per capita (less than 15-20,000 euros). The probability of transitioning from the inactive state to the unemployed state seems higher mainly among people up to approximately 40 years old (second plot of the second and third rows of Figs. 8 and 9). After this threshold, the probabilities tend to decrease independently of the level of GDP per capita. This is likely because much of the population that wants or intends to enter the labour force is already classified as either employed or unemployed.

\section{Conclusions}

As discussed by Marston (1976), traditional statistics on the employment, unemployment, and inactivity of a population cannot fully explain some issues that characterise the labour market, such as the micro- and macroeconomic factors that contribute to changes in these indicators. However, studies on labour market transitions can improve knowledge in this area. In the case of Italy, a number of scholars have explored labour market transition rates and the impacts of policies introduced with labour reforms. They have applied the concept of a transition matrix in their studies to analyse, for example, the probability of moving from one fixed-term contract to a permanent contract. They have also examined the effects of the duration of unemployment and of labour experience on the probability of finding a job, among other outcomes (see Section 1).

Despite the importance of these studies in providing fundamental insights for policymakers, to the best of our knowledge, no evidence had been provided on patterns of labour market transitions based on GDP per capita at the region level or individual age, ceteris paribus (e.g. regulatory frameworks). This analysis is important for Italy mainly for three reasons: (a) the country is characterised by economic dualism, with a large disparity between north and south in terms of GDP per capita; (b) the country is characterised by low internal labour mobility due to the frictional effects of factors such as distance, transaction costs, and regional amenities (for further details, see for example Faini et. 1997; Ward-Warmedinger and Macchiarelli 2013); and (c) the issue of unemployment, especially among the youngest generations. In light of these issues, our assumption is that a young individual who lives, for example, in a territory with optimal economic characteristics should have more labour market opportunities than one who resides in an economic territory with poor opportunities, ceteris paribus (including the regulatory framework). Under this framework, we also assume that an individual has opportunities to find (or maintain) a job in their region of residence. Hence, he/she should not be obliged to migrate from his/her residence to find a job.

To analyse the interaction effects of the levels of GDP per capita at the regional level and age on transition probabilities in the Italian labour market, we propose a flexible hierarchical logit model. We applied this method using Italian micro-level data from 
the LFS over the period 2004-2013. Compared to similar studies in the literature that consider the working age population to be between 15 and 64 years old, we focus on a population of males and females ranging from 18 to 74 years old. This is because over the last years, some people have begun working past the typical retirement age (64 years old).

We observe differences in transitions from the state of unemployment for males and females based on the age cohort and the level of GDP per capita. For example, we noted a probability of transit from unemployment to employment that was three times higher for a young male (20-30 years old) with a high school diploma, who had been unemployed for a few months (up to 6 months), who had labour experience, and who resided in a territory with a medium-high GDP per capita (more than 30,000 euros) compared to an individual with the same characteristics but who lived in an area with a low GDP per capita (less than 15-20,000 euros). This gap is important evidence that suggests how the policies introduced in recent labour market reforms (e.g. limiting precarious contracts) do not provide key ingredients needed to stimulate job growth (particularly among young people) in contexts that are economically disadvantaged. Of interest, we also noted that the probability of re-entry into the labour market is reduced with age. This decrease appears to be more gradual for males than for females.

We also observed a higher probability of transition from employment to unemployment for both genders residing in territories that are the most disadvantaged in terms of GDP per capita compared to people who live in the most economically advanced areas. Moreover, we highlighted how the transition from employment to unemployment can be a crucial for people, especially males, in the 30-50 age cohort residing in poor parts of the country and who are employed under fixed-term contracts.

Our findings reinforce the need to accompany labour market policies with structural reforms oriented towards increasing investment (of industrial and infrastructural natures) aiming to improve the economic conditions of the territory, especially in the most disadvantaged areas of the country. This is necessary in order to create the conditions that encourage the establishment of production systems that can create new jobs. There are key factors that can help stimulate economic growth and employment. One important caveat in interpreting the results is that we have limited the analysis to the working age population that remains in the same residence at both points of observation (i.e. at $T$ and at $T+12$ months).

We believe that our findings can provide direction to the debate on labour market issues. In particular, they contribute some elements to introduce and refine effective strategies on the political agenda to achieve some of the aims of the Europe 2020 plan.

\section{Endnotes}

${ }^{1}$ In studying transitions from the employed or unemployed states, the homogeneity element is defined in the concept of labour force (that includes both employed and unemployed workers). In studying transitions from a state of inactivity, we have identified the element of homogeneity in the concept of the absence of labour income (in the definition of labour income, we exclude public subsidies for unemployed workers that can be observed in the case of P01).

${ }^{2}$ In producing such information, we have considered as values of the control variables the median for continuous variables and the modal level for categorical variables. 


\section{Appendix A: a two-dimensional tensor product smoother for region-level GDP per capita and age}

The construction of a two-dimensional scale-invariant tensor product smoother for worker age (age) and region-level GDP per capita $(g d p)$ is based on two marginal onedimensional spline bases, with associated quadratic penalties measuring their roughness. Assuming that we have two low-rank bases (in our case, cubic regression splines) representing smooth functions for $f_{\text {age }}$ and $f_{\text {gdp }}$, we can write (e.g. Ruppert et al. 2003):

$$
f_{\text {age }}(\text { age })=\sum_{l=1}^{L} \alpha_{l} b_{l}(\text { age })=\mathbf{X}_{\text {age }} \boldsymbol{\alpha} \text { and } f_{\text {gdp }}(\text { gdp })=\sum_{r=1}^{R} \gamma_{r} d_{r}(\text { gdp })=\mathbf{X}_{\text {gdp }} \boldsymbol{\nu}
$$

where $b_{l}$ (age) and $d_{r}(\mathrm{gdp})$ are the known basis functions with corresponding parameters $\alpha_{l}$ and $\gamma_{r}$, and $L$ and $R$ are the spline dimensions, while $\mathbf{X}_{\mathrm{age}}$ and $\mathbf{X}_{\mathrm{gdp}}$ are the marginal model matrices considering the basis functions with parameter vectors $\xi$ and $\gamma$.

In order to set up a two-dimensional tensor product smoother for age and gdp, we need to convert $f_{\text {age }}$ (age) into a smooth function of age and gdp, that is, $f_{\text {age }}($ age $)$ has to vary smoothly with gdp (e.g. Wood 2006a; Marra et al. 2012). This can be achieved by allowing the parameter $\alpha_{l}$ to vary smoothly with gdp, which results in:

$$
f(\text { age, gdp })=\sum_{l=1}^{L} \sum_{r=1}^{R} \gamma_{l r} d_{r}(\text { gdp }) b_{l}(\text { age })
$$

Given a set of age and gdp observations, there is a relationship between the matrix $\mathbf{X}_{a g}$ assessing the tensor product smoother at these observations and the model matrices $\mathbf{X}_{\text {age }}$ and $\mathbf{X}_{\text {gdp }}$ assessing the marginal smooths at the same observations. Appropriately ordering the parameters $\gamma_{l r}$ into a vector $\boldsymbol{\theta}$, the $i$ th row of $\mathbf{X}_{a g}$ is given by $\mathbf{X}_{a g, i}=\mathbf{X}_{\mathrm{age}, i} \otimes$ $\mathbf{X}_{\mathrm{gdp}, i}$, where $\otimes$ is the Kronecker product.

In the GAM framework, the roughness of the smooth functions must be quantified in order to avoid overfitting during the parameter estimation process (e.g. Wood 2006a). As for the penalty associated with this tensor product basis, it is possible to start from roughness measures associated with the marginal smooths $f_{\text {age }}$ (age) and $f_{\text {gdp }}$ (gdp). Suppose that functions $J$ measuring the roughness of the smooth function are available, we have:

$$
J_{\text {age }}\left(f_{\text {age }}\right)=\boldsymbol{\alpha}^{\top} \mathbf{S}_{\text {age }} \boldsymbol{\alpha} \text { and } J_{\text {gdp }}\left(f_{\text {gdp }}\right)=\boldsymbol{\gamma}^{\top} \mathbf{S}_{\text {gdp }} \boldsymbol{\gamma}
$$

where the $\mathbf{S}$ matrices contain known coefficients whose values depend on the chosen bases for the two variables. Note that, in our case, the second-order cubic penalty for $f_{\text {age }}($ age $)$ is $J_{\text {age }}\left(f_{\text {age }}\right)=\int\left(\partial^{2} f_{\text {age }} / \partial a g e^{2}\right)^{2}$ dage, which is analogous for $f_{\text {gdp }}(g d p)$. Following the derivations in Augustin et al. (2009), an overall penalty for the tensor product smooth can be obtained by applying the penalties of $f_{\text {gdp }}(g d p)$ to the varying coefficients of the marginal smooth $f_{\text {age }}($ age $), \alpha_{l}(g d p)$ :

$$
\sum_{l=1}^{L} J_{\mathrm{gdp}}\left\{\alpha_{l}(\mathrm{gdp})\right\}
$$


The penalties of $f_{\text {age }}$ (age) to the varying coefficients of the marginal smooth $f_{\text {gdp }}\left(\right.$ gdp), $\gamma_{r}$ (age)

$$
\sum_{r=1}^{R} J_{\text {age }}\left\{\gamma_{r}(\text { age })\right\} \text {. }
$$

As a result, the roughness penalty of $f$ (age, gdp) can be measured as

$$
\lambda_{\text {ag }} \sum_{l=1}^{L} J_{\text {gdp }}\left\{\alpha_{l}(\text { gdp })\right\}+\lambda_{\text {age }} \sum_{r=1}^{R} J_{\text {age }}\left\{\gamma_{r}(\text { age })\right\},
$$

where $\lambda$ is a smoothing parameter controlling the trade-off between model fit and smoothness. See Wood (2006a) for further details.

\section{Appendix B: some descriptive statistics}

Table 5 Descriptive statistics of the explanatory variables included in the model of a transition from

\begin{tabular}{|c|c|c|c|c|}
\hline \multirow[b]{2}{*}{ Variables } & \multicolumn{2}{|l|}{ Men } & \multicolumn{2}{|l|}{ Women } \\
\hline & 2004 & 2012 & 2004 & 2012 \\
\hline \multicolumn{5}{|l|}{ Citizenship } \\
\hline Italian & $97.8 \%$ & $91.2 \%$ & $97.9 \%$ & $90.6 \%$ \\
\hline Foreign EU27 & $0.2 \%$ & $2.3 \%$ & $0.3 \%$ & $3.5 \%$ \\
\hline Foreign non-EU27 & $2.0 \%$ & $6.6 \%$ & $1.7 \%$ & $5.9 \%$ \\
\hline \multicolumn{5}{|l|}{ Socio-demographic factors } \\
\hline Age & $41.5(11.3)$ & $43.9(11.2)$ & $40.2(10.5)$ & $42.9(10.2)$ \\
\hline Years of education & $10.6(3.9)$ & $11.3(3.9)$ & $11.5(3.9)$ & $12.4(3.9)$ \\
\hline Share of children in the household & $0.15(0.20)$ & $0.14(0.20)$ & $0.15(0.20)$ & $0.14(0.20)$ \\
\hline \multicolumn{5}{|l|}{ Type of employment } \\
\hline Employed (permanent contract) & $61.3 \%$ & $61.3 \%$ & $67.4 \%$ & $69.0 \%$ \\
\hline Employed (fixed-term contract) & $6.4 \%$ & $8.3 \%$ & $10.4 \%$ & $11.4 \%$ \\
\hline Self-employed (collabouration) & $1.2 \%$ & $1.5 \%$ & $3.0 \%$ & $2.2 \%$ \\
\hline Self-employed (entrepreneur) & $23.7 \%$ & $21.3 \%$ & $12.8 \%$ & $10.5 \%$ \\
\hline Self-employed (freelancer) & $5.8 \%$ & $6.2 \%$ & $2.8 \%$ & $4.1 \%$ \\
\hline Self-employed (co-adjuvant of family business) & $1.7 \%$ & $1.4 \%$ & $3.7 \%$ & $2.9 \%$ \\
\hline \multicolumn{5}{|l|}{ Sector of employment } \\
\hline Agriculture & $5.7 \%$ & $5.4 \%$ & $4.0 \%$ & $3.2 \%$ \\
\hline Buildings & $13.0 \%$ & $12.6 \%$ & $1.3 \%$ & $1.1 \%$ \\
\hline Industry & $26.1 \%$ & $25.5 \%$ & $16.7 \%$ & $13.0 \%$ \\
\hline Commerce & $15.1 \%$ & $15.1 \%$ & $15.4 \%$ & $14.9 \%$ \\
\hline Services & $40.1 \%$ & $41.5 \%$ & $62.5 \%$ & $67.9 \%$ \\
\hline \multicolumn{5}{|l|}{ Size of the firm (num. of employees) } \\
\hline No employee & $20.3 \%$ & $20.3 \%$ & $14.0 \%$ & $12.6 \%$ \\
\hline Up to 10 employees & $28.1 \%$ & $27.6 \%$ & $31.4 \%$ & $35.1 \%$ \\
\hline From 11 to 49 employees & $25.7 \%$ & $25.9 \%$ & $27.0 \%$ & $27.2 \%$ \\
\hline From 50 to 250 employees & $16.4 \%$ & $16.1 \%$ & $18.8 \%$ & $15.9 \%$ \\
\hline More than 250 employees & $9.6 \%$ & $10.0 \%$ & $8.8 \%$ & $9.2 \%$ \\
\hline Number of observations & 17,257 & 12,781 & 11,512 & 9451 \\
\hline
\end{tabular}
the status of employed

Here, we report only the evidence for two periods of observation (state of employed at time T): 2004 and 2012. The complete analysis is available upon request. For binary and categorical variables, we report the distribution of observations in percentage terms. For continuous variables, the mean and standard deviation (within parentheses) are reported instead 
Table 6 Descriptive statistics of the explanatory variables included in the model of a transition from the unemployed state

\begin{tabular}{|c|c|c|c|c|}
\hline \multirow[b]{2}{*}{ Variables } & \multicolumn{2}{|l|}{ Men } & \multicolumn{2}{|l|}{ Women } \\
\hline & 2004 & 2012 & 2004 & 2012 \\
\hline \multicolumn{5}{|l|}{ Citizenship } \\
\hline Italian & $97.2 \%$ & $87.1 \%$ & $96.4 \%$ & $85.0 \%$ \\
\hline Foreign EU27 & $0.1 \%$ & $3.5 \%$ & $0.3 \%$ & $5.7 \%$ \\
\hline Foreign non-EU27 & $2.7 \%$ & $9.4 \%$ & $3.3 \%$ & $9.3 \%$ \\
\hline \multicolumn{5}{|l|}{ Socio-demographic factors } \\
\hline Age & $34.4(12.0)$ & $36.5(12.5)$ & $33.9(10.2)$ & $35.4(10.9)$ \\
\hline Years of education & $9.7(3.7)$ & $10.0(3.6)$ & $10.6(3.7)$ & $11.3(3.7)$ \\
\hline Share of children in the household & $0.10(0.17)$ & $0.10(0.17)$ & $0.15(0.20)$ & $0.14(0.20)$ \\
\hline \multicolumn{5}{|l|}{ Labour experience } \\
\hline Yes & $78.2 \%$ & $81.1 \%$ & $77.6 \%$ & $73.1 \%$ \\
\hline No & $21.8 \%$ & $18.9 \%$ & $28.4 \%$ & $26.9 \%$ \\
\hline \multicolumn{5}{|l|}{ Duration of job search } \\
\hline Up to 6 months & $37.9 \%$ & $36.9 \%$ & $35.2 \%$ & $35.8 \%$ \\
\hline Between 7 and 12 months & $16.0 \%$ & $17.7 \%$ & $17.6 \%$ & $22.8 \%$ \\
\hline Between 13 and 24 months & $13.5 \%$ & $19.4 \%$ & $14.8 \%$ & $17.1 \%$ \\
\hline Greater than 25 months & $25.2 \%$ & $23.7 \%$ & $29.1 \%$ & $22.9 \%$ \\
\hline Unknown & $7.4 \%$ & $2.2 \%$ & $3.3 \%$ & $1.5 \%$ \\
\hline Number of observations & 1193 & 1437 & 1385 & 1296 \\
\hline
\end{tabular}

Here, we report only the evidence for two periods of observation (state of unemployed at time T): 2004 and 2012. The complete analysis is available upon request. For binary and categorical variables, we report the distribution of observations in percentage terms. For continuous variables, the mean and standard deviation (within parentheses) are reported instead

Table 7 Descriptive statistics of the explanatory variables included in the model of a transition from the status of inactive

\begin{tabular}{|c|c|c|c|c|}
\hline \multirow[b]{2}{*}{ Variables } & \multicolumn{2}{|l|}{ Men } & \multicolumn{2}{|l|}{ Women } \\
\hline & 2004 & 2012 & 2004 & 2012 \\
\hline \multicolumn{5}{|l|}{ Citizenship } \\
\hline Italian & $99.3 \%$ & $92.8 \%$ & $98.5 \%$ & $92.8 \%$ \\
\hline Foreign EU27 & $0.1 \%$ & $1.6 \%$ & $0.2 \%$ & $1.9 \%$ \\
\hline Foreign non-EU27 & $0.6 \%$ & $5.5 \%$ & $1.3 \%$ & $5.3 \%$ \\
\hline \multicolumn{5}{|l|}{ Socio-demographic factors } \\
\hline Age & $35.0(17.0)$ & $35.9(16.3)$ & $40.0(15.7)$ & $39.8(15.8)$ \\
\hline Years of education & $9.4(4.2)$ & $9.7(3.8)$ & $8.41(3.7)$ & $9.34(3.7)$ \\
\hline Share of children in the household & $0.05(0.13)$ & $0.06(0.13)$ & $0.12(0.18)$ & $0.12(0.18)$ \\
\hline \multicolumn{5}{|l|}{ Labour experience } \\
\hline Yes & $56.5 \%$ & $52.2 \%$ & $57.5 \%$ & $47.5 \%$ \\
\hline No & $43.5 \%$ & $47.8 \%$ & $42.5 \%$ & $52.5 \%$ \\
\hline \multicolumn{5}{|c|}{ Status of the individual out of labour force } \\
\hline Student & $44.0 \%$ & $36.0 \%$ & $13.1 \%$ & $13.5 \%$ \\
\hline Housewife & - & - & $71.4 \%$ & $69.9 \%$ \\
\hline Invalid & $18.2 \%$ & $14.1 \%$ & $3.6 \%$ & $3.0 \%$ \\
\hline In other condition & $37.8 \%$ & $49.9 \%$ & $11.9 \%$ & $13.6 \%$ \\
\hline Number of observations & 3254 & 2888 & 13,059 & 9600 \\
\hline
\end{tabular}

Here, we report only the evidence for two periods of observation (state of inactive at time T): 2004 and 2012. The complete analysis is available upon request. For binary and categorical variables, we report the distribution of observations in percentage terms. For continuous variables, the mean and standard deviation (within parentheses) are reported instead 
Table 8 Gross domestic product per capita in euros by region (chained values, base year: 2005). The data reported are from ISTAT

\begin{tabular}{|c|c|c|}
\hline Regions & 2004 & 2012 \\
\hline \multicolumn{3}{|l|}{ North West } \\
\hline Piemonte & 27,457 & 24,910 \\
\hline Valle d'Aosta & 33,012 & 30,843 \\
\hline Lombardia & 31,283 & 29,434 \\
\hline Liguria & 25,749 & 24,269 \\
\hline \multicolumn{3}{|l|}{ North East } \\
\hline Trentino Alto Adige & 30,912 & 29,358 \\
\hline Friuli Venezia Giulia & 27,073 & 25,986 \\
\hline Veneto & 28,684 & 26,232 \\
\hline Emilia Romagna & 30,342 & 28,211 \\
\hline \multicolumn{3}{|l|}{ Central Italy } \\
\hline Toscana & 26,493 & 25,074 \\
\hline Umbria & 23,410 & 20,462 \\
\hline Marche & 24,777 & 22,793 \\
\hline Lazio & 29,466 & 26,198 \\
\hline \multicolumn{3}{|l|}{ South } \\
\hline Abruzzo & 19,899 & 19,316 \\
\hline Molise & 18,724 & 17,035 \\
\hline Campania & 15,786 & 14,422 \\
\hline Puglia & 16,381 & 15,162 \\
\hline Basilicata & 16,685 & 15,692 \\
\hline Calabria & 15,806 & 14,383 \\
\hline \multicolumn{3}{|l|}{ Islands } \\
\hline Sicilia & 15,625 & 14,521 \\
\hline Sardegna & 18,283 & 17,162 \\
\hline Italy & 24,463 & 22,807 \\
\hline
\end{tabular}

\section{Acknowledgements}

The research was funded by ESRC Impact Acceleration Accounts. We thank the participants of the 48th Scientific Meeting of the Italian Statistical Society for their helpful suggestions. We would like to thank two anonymous reviewers for many suggestions that helped to improve the presentation and quality of the article. The opinions expressed herein are those of the authors and do not reflect those of the institution of affiliation.

Responsible editor: Joni Hersch

\section{Competing interests}

The IZA Journal of Labor Economics is committed to the IZA Guiding Principles of Research Integrity. The authors declare that they have observed these principles.

\section{Publisher's Note}

Springer Nature remains neutral with regard to jurisdictional claims in published maps and institutional affiliations.

\section{Author details}

${ }^{1}$ Prometeia, G. Marconi, Bologna 40122, Italy. ${ }^{2}$ The University of Edinburgh Business School, 29 Buccleuch Place, Edinburgh EH8 9JS, UK.

Received: 24 November 2016 Accepted: 6 March 2017

Published online: 21 April 2017

\section{References}

Augustin NH, Musio M, Wilpert K, Kublin E, Wood SN, Schumacher M (2009) Modeling spatiotemporal forest health monitoring data. J Am Stat Assoc 104:899-911

Arechavala NS, Espina PZ, Trapero BP (2015) The economic crisis and its effects on the quality of life in the European Union. Soc Indic Res 120:323-343

Baussola M, Mussida C, Jenkins J, Penfold M (2015) Determinants of the unemployment gender gap: a comparative investigation. Int Labour Rev 154:537-562 
Baussola M, Mussida C (2014) Transitions in the labour market: discouragement effect and individual characteristics. Labour 28:209-232

Barbieri P, Scherer S (2009) Labour market flexibilization and its consequences in Italy. Eur Sociol Rev 25:677-692 Barbieri G, Sesisto P (2008) Temporary Workers in Italy: Who Are They and Where They End Up. Labour 22:127-166 Berton F, Devicienti F, Pacelli L (2011) Are temporary jobs a port of entry into permanent employment? Evidence from matched employer-employee data. Int J Manpow 32:879-899

Buyse T, Heylen F, Van de Kerckhove R (2013) Pension reform, employment by age, and long-run growth in OECD countries. J Popul Econ 26:769-809

Blundell R, Magnac T, Meghir C (1997) Savings and labour-market transitions.J Bus Econ Stat 15:153-164

Cirillo V, Guarascio D (2015) Jobs and Competitiveness in a polarised Europe. Intereconomics 50:156-160

Constant AF, Zimmermann KF (2014) Self-employment against employment or unemployment: Markov transitions across the business cycle. Eurasian Bus Rev 4:51-87

Contini B, Rapiti FM (1999) Young In, Old Out' Revisited: New Patterns of Employment Replacement in the Italian Economy. International Review of Applied Economics 13:395-415

Curci N, Mariani V (2013) Le transizioni nel mercato del lavoro italiano: una prospettiva di genere (Labour Market Transitions in Italy: A Gender Perspective). Bank of Italy Occasional Paper No. 173. Available at SSRN: https://ssrn.com/ abstract $=2297301$

Dreger C, Reimers H-E (2016) Does public investment stimulate private investment? Evidence for the euro area, Economic Modelling 58:154-158

Edely M (2009) The global financial crisis and its effects. Econ Papers J Appl Econ Policy 85:207-234

Egger P, Pfaffermayr M, Weber A (2007) Sectoral adjustment of employment to shifts in outsourcing and trade: evidence from a dynamic fixed effects multinomial logit model. J Appl Econ 22(3):559-580

Eichhorst W, Boeri T, de Coen A, Galasso V, Kendzia MJ, Steiber N (2013) How to combine the entry of young people in the labour market with the retentions of older workers? IZA Discussion paper Series No:7829

Faini R, Galli G, Gennari P, Rossi F (1997) An empirical puzzle: falling migration and growing unemployment differentials among Italian regions. Eur Econ Rev 41:571-579

Fana M, Guarascio D, Cirillo V (2015) Labour market reforms in Italy: evaluating the effects of the Jobs act. Working Paper n. 5/2015, Sant'Anna School of Advanced Studies

Fabrizi E, Mussida C (2009) The determinants of labour market transitions. Giornale degli Economisti 68:233-265

Flint E, Shelton N, Bartley M, Sacker A (2013) Do local unemployment rates modify the effect of individual labour market status on psychological distress? Health Place 23:1-8

Flisi S, Morciano M (2011) Trends and dynamics in the Italian labour market. An empirical evaluation using RFL data, 1993-2007. Working Paper n. 661, Department of Economics, University of Modena and Reggio Emilia

Gagliarducci S (2005) The dynamics of repeated temporary jobs. Labour Econ 12:429-448

Ghoshray A, Ordonez J, Sala H (2016) Euro, crisis and unemployment: youth patterns, youth policies? Economic Modelling 58:442-453

Hersch J, Stratton LS (1997) Housework, fixed effects, and wages of married workers. J Hum Resour 32:285-307

International Monetary Found (2014) Fiscal monitor - back to work: how fiscal policy can help, Washington. http://www. imf.org/external/pubs/ft/fm/2014/02/fmindex.htm

Ward-Warmedinger M, Macchiareli C (2013) Transitions in labour market status in the EU. IZA Working Paper n:7814

Marra G, Miller DL, Zanin L (2012) Modelling the spatiotemporal distribution of the incidence of resident foreign population. Statistica Neerlandica 66:133-160

Mazzola P, Rimoldi SML, Rossi P, Noale M, Rea F, Facchini C, Maggi S, Corrao G, Annoni G (2015) Aging in Italy: the need for new welfare strategies in an old country. Gerontological. doi:10/1093/geront/gnv152

Marston ST (1976) Employment instability and high unemployment rate. Brook Pap Econ Act 1:169-203

McFadden DL (1973) Conditional logit analysis of qualitative choice behavior. In: Zarembka P (ed). Frontiers in Econometrics. Academic Press, New York. pp 105-142

Mussida (2010) Is Long-term Unemployment Unaffected by Flexible Labour Market Legislation?. Rivista Internazionale di Scienze Sociali Anno 118:77-105

Keith K, McWilliams A (1999) The returns to mobility and job search by gender. Ind Labour Relat Rev 52:460-477

Ouimet P, Zarutskie R (2013) Who works for startups? The relation between firm age, employee age, and growth. Finance and Economics Discussion Series 2013-75, Board of Governors of the Federal Reserve System (U.S.)

Pacelli L, Pasqua S, Villosio C (2013) Labour market penalties for mothers in Italy. J Labour Res 34:408-432

Papoulis A (1984) Probability, random variables and stochastic processes. McGraw-Hill, New York

Pastore F (2012) Youth unemployment in Italy at the time of the new Great Depression. Working paper. Friedrich Ebert Stiftung

Pestieau P, Racionero M (2016) Harsh occupations, life expectancy and social security, Economic Modelling 58:194-202

Picchio M (2008) Temporary contracts and transitions to stable jobs in Italy. Labour 22:147-174

Poterba JM, Summers LH (1995) Unemployment benefits and labour market transitions: a multinomial logit model with errors in classification. Rev Econ Stat 77:207-216

Rupert D, Wand MP, Carrol RJ (2003) Semiparametric regression. Cambridge University Press, London

Shimer R (2012) Reassessing the ins and outs of unemployment. Rev Econ Dyn 15:127-148

Theodossiou I (2002) Factors affecting the job to joblessness turnover and gender. Labour 16:729-746

Theodossiou I, Zangelidis A (2009) Should I stay or should I go? The effect of gender, education and unemployment on labour market transitions. Labour Econ 16:566-577

Tutz G (2012) Regression for categorical data. Cambridge University Press, New York

Wood SN (2006a) Generalized additive models: an introduction with R. Chapman \& Hall, London

Wood SN (2006b) Low rank scale invariant tensor product smooths for generalized additive mixed models. Biometrics 62:1025-1036

Zanin L, Marra G (2012) Rolling regression versus time-varying coefficient modelling: an empirical investigation of the Okun's law in some Euro area countries. Bull Econ Res 64:91-108

Zanin L (2014) On Okun's law in OECD countries: an analysis by age cohorts. Econ Lett 125:243-248

Zanin L (2016) The pyramid of Okun's coefficient for Italy. Empirica J Eur Econ. doi:10.1007/s10663-016-9343-5 